\title{
LEARNING TO FLY: THE UNTOLD HISTORY OF HOW THE WRIGHT BROTHERS LEARNED TO BE THE WORLD'S FIRST AERONAUTICAL ENGINEERS
}

\author{
A Thesis \\ presented to \\ the Faculty of California Polytechnic State University, \\ San Luis Obispo
}

In Partial Fulfillment

of the Requirements for the Degree

Master of Arts in History

By

Daniel Lawrence Slusser

April 2011 


\section{Copyright 2011}

Daniel Lawrence Slusser

ALL RIGHTS RESERVED 
COMMITTEE MEMBERSHIP

TITLE:

LEARNING TO FLY: THE UNTOLD STORY OF

HOW THE WRIGHT BROTHERS LEARNED TO BE

THE WORLD'S FIRST AERONAUTICAL

ENGINEERS

AUTHOR: Daniel Lawrence Slusser

DATE SUBMITTED:

April 2011

COMMITTEE CHAIR: Dr. Matthew S. Hopper, PhD

COMMITTEE MEMBER: $\quad$ Dr. George B. Cotkin, PhD

COMMITTEE MEMBER: $\quad$ Dr. Robert Detweiler, PhD

COMMITTEE MEMBER: $\quad$ Dr. Joel Orth, PhD

COMMITTEE MEMBER: $\quad$ Bruce R. Wright 


\begin{abstract}
LEARNING TO FLY: THE UNTOLD STORY OF HOW THE WRIGHT BROTHERS
\end{abstract}

LEARNED TO BE THE WORLD'S FIRST AERONAUTICAL ENGINEERS

Daniel Lawrence Slusser

This paper examines the education, events, and experiences of the Wright brothers in order to determine how they developed the necessary skills to engineer the first viable aircraft. Without high school diplomas, and with no advanced formal education, the Wright brothers were able to develop aircraft that far exceeded the capabilities of aircraft designed and built by professional engineers that had worked on the problem of flight for much longer and with substantially larger research budgets. I argue that the Wright brothers' success resulted from their experiences in the printing and bicycle industries as well as their formal and informal educations at school and in the home.

In the printing business it was their experiences designing and building printing presses, printing newspapers, and operating a job printing shop that taught them how to build machinery and work efficiently and methodically. These same skills were perfected as the Wright brothers managed their second business venture: The Wright Cycle Exchange.

While working at the bicycle shop the Wrights learned to be proficient machinists as well as expert mechanics and frame builders. This industry provided them with many skills such as brazing and machining that would be directly applicable to aircraft fabrication. In addition to these skills, building bicycle frames and wheels taught them practical material limits and structural design that informed their aircraft design decisions. Moreover, bicycle design influenced their approach to aircraft control and aerodynamic theory that gave them an edge over other aeronautical experimenters in their race to the sky.

When these skills were combined with their rigid religious upbringing, the Wright brothers were uniquely prepared to solve the complex problem of practical human flight. It was the combination of their fabrication skills, understanding of material limits, dogged determination, methodical testing procedures, and their unique approach to aircraft control that was informed by their experiences with bicycles that made them the first in flight.

Keywords: Wright brothers, early aviation, bicycles, printing, engineering, aircraft, Orville Wright, Wilbur Wright, Milton Wright. 


\section{ACKNOWLEDGMENTS}

Any project of this magnitude is indebted to the efforts of numerous scholars, colleagues, archivists, friends and family. I would like to first thank the professors who worked with me thought the thesis process including Doctors George Cotkin, Robert Detweiler, Matt Hopper, Joel Orth, and Tom Trice who have graciously put forth many hours reviewing drafts on their own time without financial compensation for their labors. I also want to extend a special thanks to Bruce R. Wright, a former project manager at the legendary Lockheed Skunk Works, for serving on my committee and reviewing the aeronautical engineering references contained within my thesis.

National Park Service historian Ed Roach at the Wright brothers' 22 South Williams bike shop location in Dayton has been invaluable in providing documentation regarding the specifics of the Wrights' tools and the bicycles they made with them. Archivist John Armstrong at the Wright State University archives has also been very helpful in providing access to the many Wright documents and books housed within the Paul Laurence Dunbar library.

Laura Sorvetti, curator at the Shakespeare Press Museum on the Cal Poly campus, has also been quite helpful in explaining nineteenth century printing technology. She politely endured hours of my rapid fire questions on the minutiae of late nineteenthcentury printing technology with grace.

Of course any study of the Wright brothers would be infinitely more difficult without the work of Marvin McFarland and Tom Crouch who have invested so many years toward providing exhaustive documentation of the lives of the Wright brothers. Their work has placed all of the vital information in just a few books comprising what I refer to as "the bible of Wright brothers' history."

Most of all I would like to thank my beautiful wife Sara for the many sacrifices she has made to assist me as I researched and wrote this thesis. Often these sacrifices came at the expense of her health. Her devotion has been appreciated immeasurably and I truly feel unworthy of the overwhelming sacrifice this assistance represents. 


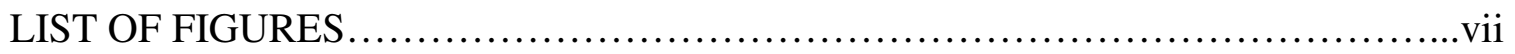

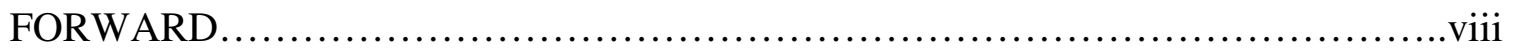

\section{CHAPTER}

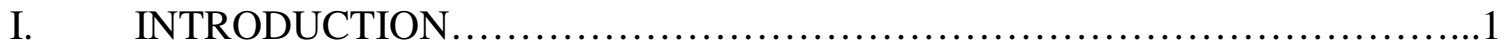

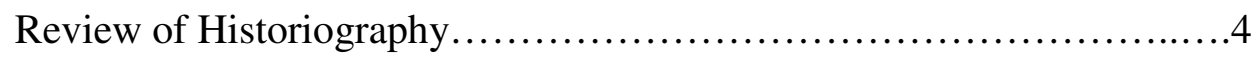

Methodology and Conclusion...................................... 9

II. A SOCIAL CONTEXT FOR THE WRIGHT BROTHERS .....................14

III. THE EARLY YEARS: FAMILY AND PRINTING..........................21

IV. BICYCLES AND THEIR OFFSPRING .................................27

V. TAKING TO THE AIR.........................................................

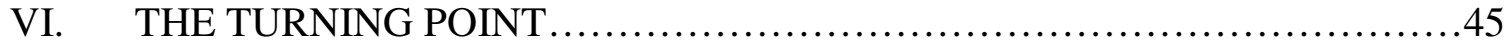

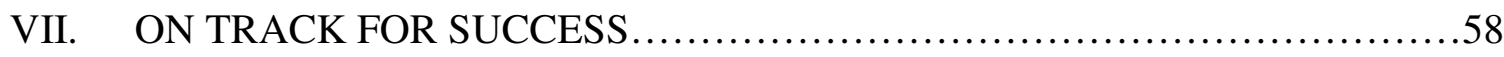

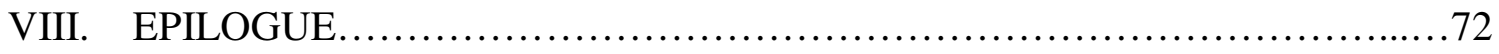

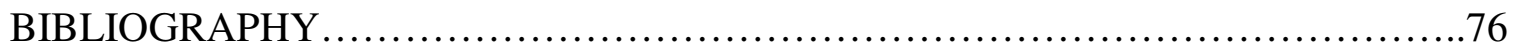




\section{LIST OF FIGURES}

Figure

Page

1. Ishihara Colorblindness Test....................................................

2. Orville Wright bicycle racing medals.....................................29

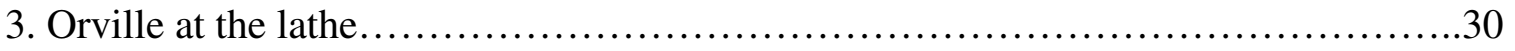

4. The Wright brothers' first airfoil testing rig.................................49

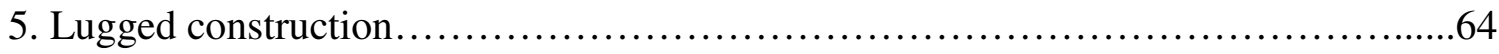

6. Similarities between Wright aircraft structures and bicycle frames................65

7. Fragment of wing warping control linkage.................................66 


\section{FORWARD}

The subject of my thesis seems to have fallen into my hands as if by destiny. The circumstances of my life have led to a number of shared experiences to those of the Wright brothers. My obsession with airplanes as a child drove me to begin taking flying lessons at age fifteen, spending every cent I earned working as a drug store clerk on airplane rentals and instructor fees.

After flying solo multiple times at age sixteen, I obtained the first of many jobs working in a bike shop. These jobs would develop a defining aspect of my life that I share with the Wrights, a love of cycling. During this same time my father was serving as a bishop in a Christian church just as the Wright brothers' father did. Like Wilbur and Orville, I also know what it is like to grow up in a home where rigid obedience to scripture was strictly enforced.

Also like the Wright brothers, I have found myself employed in many seemingly unrelated fields and I am fascinated by diverse subjects. An incomplete list of my many occupations includes: emergency medical technician, flower delivery boy, mortgage loan officer, medical respiratory equipment technician, construction superintendent, bicycle mechanic, and retail clerk. My interests have been equally unrelated and include flying, camping, metalwork and machining, apparel design, cycling, cooking, playing guitar, and learning as much as I am able to. In fact, my drive to learn diverse subjects led me away from my undergraduate training as a businessman toward a graduate degree in history that held the promise of learning new facts and skills that proved too tempting to pass up.

These experiences have endeared the Wright brothers to me and created a sense of kinship that has drawn me to their history. It is my hope that the experiences that I share with the Wrights will allow me to provide a few new insights on this well documented pair. With any luck this study will reveal a new way to view the history of the Wright brothers that will challenge existing notions while providing a deeper understanding of how they became the "fathers of flight." 


\section{CHAPTER 1}

\section{INTRODUCTION}

Do you not insist too strongly upon the single point of mental ability? To me it seems that a thousand other factors, each rather insignificant in itself, in the aggregate influence the event ten times more than mere mental ability or inventiveness... [our success] was due to peculiar combinations of circumstances which might never occur again. - Wilbur Wright Oct. 28, $1906 .{ }^{1}$

This quote suggests that Wilbur Wright did not see himself as a gifted inventor but rather as an individual that was at the right place at the right time. Was it simply fate that in 1903 two brothers from Dayton, Ohio cracked the code of human flight that had confounded and fascinated humankind for millennia? Orville Wright seemed to express a certain feeling of destiny when he wrote, "Isn't it astonishing that all these secrets have been preserved for so many years just so that we could discover them!!"2 While I do not believe that the Wright Brothers attributed the bulk of their success to fate, they clearly attributed some of it to this. Nevertheless, what I believe Wilbur was really referring to when he wrote of "peculiar combinations of circumstances" is that there were many events and experiences in the Wright Brothers' lives that prepared them to be the world's first heavier-than-air aviators. Most of them are overlooked because, as Wilbur wrote, "each is rather insignificant in itself."

What were the circumstances that led to one of the greatest inventions of all time? How did the Wright Brothers gain the ability to outthink and work faster than the best minds of the time that had access to greater amounts of money, the use of more specially

\footnotetext{
${ }^{1}$ Wilbur Wright and Orville Wright. The Papers of Orville and Wilbur Wright: including the Chanute-Wright letters and other Papers of Octave Chanute, ed. By Marvin W. McFarland, (New York: McGraw-Hill, 2001), 731-732.

2 Ibid, 310-315.
} 
skilled technicians and assistants, more machine tools, and much more available man hours in which to develop an aircraft?

It seems that nearly everyone knows that the Wright Brothers were bicycle mechanics before they were aeronautical engineers, and most histories mention this fact somewhere in passing within the first paragraph or page. Yet, few people among the general population know that the Wright Brothers were also in the printing business, even though they spent more time in printing than they did in bicycles. ${ }^{3}$ Interestingly, both of these earlier occupations are often treated by historians as simply a quirky aspect of the brothers' lives bearing little serious intellectual or material connection to their development of aircraft. Compared to these two entrepreneurial efforts it seems that even less attention is paid to the development of their intellect at home and school and how this influenced their work in aircraft.

If the Wright Brothers' success was so dependent upon specific "combinations of circumstances," then why are these circumstances so often ignored or treated lightly by historians? The bicycle connection in particular seems to be lost on many. Many aviation enthusiasts in the 1890's didn't see it this way. They saw the bicycle as an important step in the development of aircraft that soon followed.

To learn to wheel one must learn to balance. To learn to fly one must learn to balance. - James Howard Means in Aeronautical Annual, $1896 .{ }^{4}$

the study to produce a light, swift [bicycle] is likely to lead to an evolution in which wings will play a conspicuous part. - The Binghamton Republican June 4, $1896 .^{5}$

\footnotetext{
${ }^{3}$ Charlotte K. Brunsman and August E. Brunsman, "Wright \& Wright Printers: The Other Career of Wilbur and Orville," The Journal of the American Printing History Assocation, Vol 10, no. 1, (1988).

${ }^{4}$ Fred C. Fisk and Marlin W. Todd, The Wright Brothers: From Bicycle to Biplane, (West Milson, Ohio: Fred C. Fisk and Marlin W. Todd, 1995), 37.
} 
I think that your consideration on the development between the flying machine and the bicycle... is excellent. I am sure the flying apparatus will have a similar development. - Otto Lilienthal, $1896 .^{6}$

there is no doubt that man will acquire this skill [of flying] with marvelous rapidity, approaching, if not equaling, that exhibited by him in the use of the bicycle... - Charles M. Manley, circa 1899 to $1903 .^{7}$

It appears that there was a consensus around the turn-of-the-century among many who intensely studied the problem of human aviation that there was a profound connection between the bicycle and the airplane. ${ }^{8}$ In an article on the connection between the Wright Brothers' work in bicycles and their work in airplanes, Tom Crouch describes the Wright Brothers as "engineers of genius who happened to be bicycle makers.", Instead, I argue that the Wright Brothers' genius was formed during their work as entrepreneurs in the printing and bicycle businesses. Their work in these industries was not simply a diversion for two of the greatest minds of their time as some historians have suggested. ${ }^{10}$ It was these experiences as well as their education at home that developed their powerful intellects and gave them the ability to build the things they dreamed of.

\footnotetext{
${ }^{5}$ Tom D.Crouch "Why Wilbur and Orville? Some Thoughts on the Wright Brothers and the Process of Invention," In Inventive Minds: Creativity in Technology, edited by Robert J. Weber and David N. Perkins, 80-92. (New York: Oxford University Press, 1992).

${ }^{6}$ Ibid.

${ }^{7}$ Samuel Pierpont Langley, Memoir on Mechanical Flight part 1, (New York: Smithsonian Institution Press: 1973), 186-187. Manley was an assistant to Langley and the inventor of the radial aircraft engine.

${ }^{8}$ C.R. Roseberry, Glenn Curtiss: Pioneer of Flight, (Garden City, New York: Doubleday, 1972), 11-17. Glenn Curtiss was another example of an aviation pioneer that got his start as a bicycle racer turned, bicycle mechanic/bike shop owner.

${ }^{9}$ Tom D. Crouch, "How the Bicycle Took Wing," Invention \& Technology Magazine, Vol. 2, Issue no. 1 (Summer 1986).

${ }^{10}$ Ann Honious, What Dreams We Have: The Wright Brothers and Their Hometown of Dayton, $O H$, (United States: Eastern National, 2003), 93.
} 


\section{REVIEW OF HISTORIOGRAPHY}

The aeronautical accomplishments of the Wright Brothers have been well documented by numerous historians and engineers over the years. Some standouts include Tom Crouch, Stephen B. Goddard, T. A. Heppenheimer, Fred Howard, Ann Honious, Peter Jakab, and Fred Kelly to name a few. ${ }^{11}$ While each of these histories contain valuable information on the Wright Brothers' development of the first aircraft, few pages are devoted to understanding what techniques and knowledge the brothers gathered during their time as entrepreneurs in the 1890's that prepared them for the invention that came to define their lives. For example, Fred Howard's Wilbur and Orville devotes just five out of four-hundred and forty pages to this critical time in their lives. ${ }^{12}$

Ann Honious' book What Dreams We Have: The Wright Brothers and Their Hometown of Dayton, Ohio aims to place the Wrights within an organic context that does not isolate their work at Kitty Hawk from the rest of their lives. ${ }^{13}$ Honious does a commendable job of this with respect to her depiction of the cultural and economic environment of turn-of-the-century Dayton by investigating Dayton newspapers from the period as well as the Wright's documents. However, she does not argue that there was a strong connection between what the Wright Brothers did in printing and bicycles to their work in aircraft. Instead, Honious attributes their success primarily to their careful experimentation methods.

In the conclusion of her chapter on the Wrights' bicycle business she sums up the importance of this business by simply writing that it produced income, served as "an

\footnotetext{
${ }^{11}$ A more extensive, but nowhere near exhaustive list of Wright biographies can be found in the annotated bibliography beginning on page 78 .

${ }^{12}$ Fred Howard, Wilbur and Orville: A Biography of the Wright Brothers, (New York: Alfred A. Knopf, 1987), 8-12.

${ }^{13}$ Ibid, 8-10.
} 
outlet for their interest in machinery and hands-on work," and "developed their mechanical skills that their parents had encouraged since childhood." ${ }^{, 14}$ Far more attention is paid by Honious to the aerodynamic developments of the Wright Brothers and the testing procedures used to evaluate them than in searching for an answer to what seems to be an obvious question in my estimation, "What experiences enabled the Wright Brothers to conceive of the questions they asked, develop the tests to evaluate these questions, and gain the ability to build their experimental aircraft and the equipment to evaluate it?"

Peter Jakab has made a conscientious effort to understand the thought processes of the Wright Brothers and how they approached their study of flight. He writes in his introduction to Visions of a Flying Machine: The Wright Brothers and the Process of Invention that,

It takes the reader through their research and experiments step by step, illustrating how Wilbur and Orville worked through each major problem. If close attention is paid to their methodology, it becomes quite apparent that there were a number of specific personality traits, innate skills, and particular research techniques present in the Wrights' approach that came together in a unique way and largely explain why these two men invented the airplane. In short, the Wrights had a definable method that in very direct terms led them to the secrets of flight. ${ }^{15}$

Jakab accomplishes what he sets out to do. He analyzes the testing methodology of the Wright Brothers during their work on kites, gliders, wings, propellers, and airplanes. This is facilitated by Jakab's examination of the Wright Brothers' writings, drawings, and photographs. However, even though he identifies in his introduction that they possessed "specific personality traits" and "innate skills" that "explain why these two men invented the airplane" he does not delve into how these skills and personality traits were developed in any structured way. While he does mention from time to time that some concepts were

\footnotetext{
${ }^{14}$ Honious, 93.

${ }^{15}$ Peter L. Jakab, Visions of a Flying Machine: The Wright Brothers and the Process of Invention, (Washington D.C.: Smithsonian Institution Press, 1990), Xv.
} 
inspired by bicycles, he does not attempt to explain how the Wright Brothers gained their ability to generate radically new ideas on human flight and how they obtained the skills needed to construct a machine that had never been made before.

To be fair, Honious and Jakab made a serious effort to document this portion of their lives and they identify some connections between the Wrights' work in bicycles and their work in aircraft. However, their narrow focus on the pioneering aerodynamic achievements of the Wright Brothers seems to have blinded them to the value of the Wright Brothers' formative years that seem to fade into the background. To employ a metaphor, I see this problem as akin to colorblindness. Below is an example of an Ishihara colorblindness test.
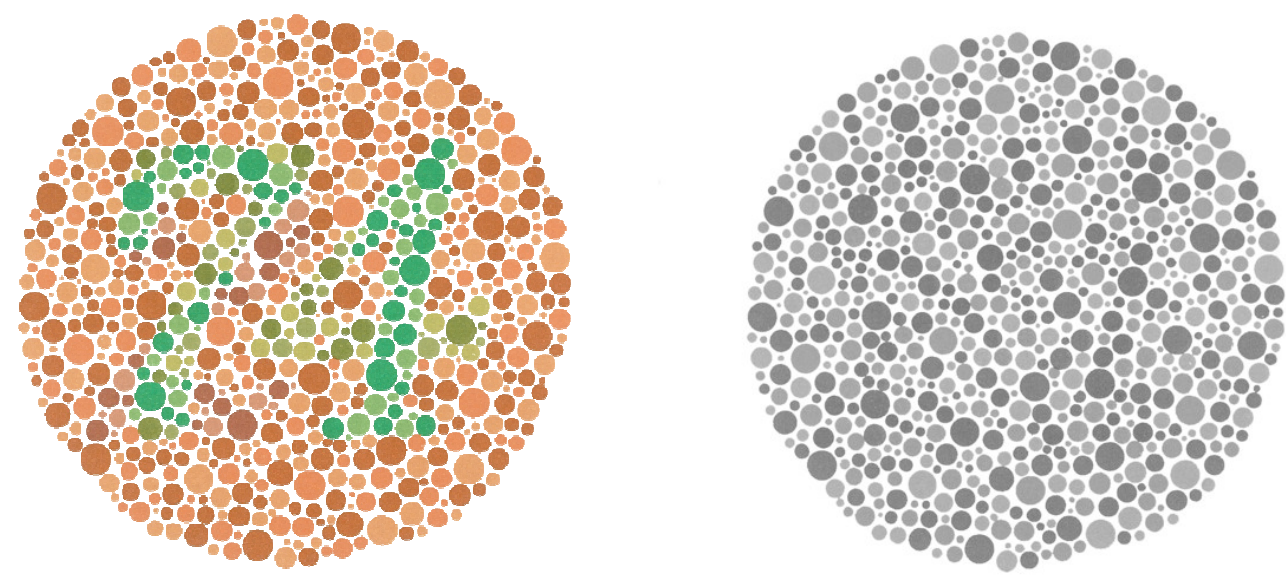

Figure 1: Ishihara Colorblindness Test (left), same test shown without color (right).

It is made up of a series of dots intended to obscure a figure within it to a colorblind patient. If the patient has a form of colorblindness that includes these colors, they will still clearly see all of the dots within the greater circle. However, in severe cases they will 
not see any numbers within the picture, only dots. A partially colorblind patient will see the number 71, and a fully color seeing patient will see the number 74. I don't believe that past historians have missed the dots that I see as representative of the formative events in the Wright Brothers' lives. These historians can clearly see the dots, and in sharp focus. However, they fail to adequately connect these dots in order to construct an accurate picture of what is before them.

Why is this? Perhaps it is because the humble bicycle is seen as too far removed from the sophisticated complexity of an aircraft? While this might play a role, I think that the most likely explanation is that many of the historians that have written about the Wright Brothers were attracted to the subject because of a love of aviation and its history. This affection for the subject has led them to focus on the aspects of the Wright Brothers' lives that interest them the most. Tom Crouch and Peter Jakab both work as aviation history curators at the Smithsonian Institute. Not surprisingly, their work on the Wright Brothers is clearly focused on their aerodynamic achievements, and Crouch and Jakab do an excellent job in documenting this aspect of the Wrights' history. However, they neglect the aspects of the Wright Brothers' lives that lie outside of their area of vast expertise.

Engineering historians of the Wright Brothers, such as John D. Anderson Jr. (also at the Smithsonian), tend to hail from the aerospace community and so they also ignore the portion of the Wright Brothers' history before they began to physically construct wings. A glaring example of this can be found in an article written by Anderson concerning the Wright brothers' engineering ability that was evident in their work on the 1903 flyer. He writes, "The fact that the Wrights, with no prior experience with any type 
of internal combustion engine, were able to design and build a successful engine [for the 1903 flyer]... is truly amazing. (emphasis added)"16 This statement ignores that the Wright brothers had already made an internal combustion engine in 1896 to power the machine tools in their bicycle shop and made a second engine for the same purpose in 1900. ${ }^{17} 18$

In some cases the connection between these early experiences are left out because, when viewed in the totality of their achievement, they seem to be insignificant by comparison. Tom Crouch wrote, "there were thousands of cycle makers active in the United States during the 1890s, and only two of them invented the airplane... the ability to identify and apply the lessons of cycling required a conceptual grasp and vision far beyond the capacity of the average cycle mechanic." ${ }^{19}$ While obviously correct, I feel that the connection between the Wright Brothers' work in bicycles and airplanes has not been explored in the depth that it deserves. A closer look will reveal that there are many connections that have been overlooked leading to a misunderstanding of who the Wright Brothers were and how they achieved what they did.

\footnotetext{
${ }^{16}$ John D. Anderson Jr., "The Wright Brothers: The First True Aeronautical Engineers," in The Wright Flyer: An Engineering Perspective, ed. Howard S. Wolko, 1-17 (Washington D.C.: Smithsonian Institution Press, 1987), 16.

${ }^{17}$ Tom D. Crouch, The Bishop's Boys: A Life of Wilbur and Orville Wright, (New York: W.W. Norton \& Company, 1989), 112-113.

18 The 1900 motor still exists today and is on display in Greenfield Village, Michigan. See: Kathryn A. Keefer, The Wright Cycle Shop Historical Report, (Greenfield Village, Michigan: The Henry Ford, 2005), 80-81.

${ }^{19}$ Crouch, "How the Bicycle Took Wing;" Peter Jakab repeats this sentiment with almost identical language in Visions of a Flying Machine, page 10.
} 


\section{METHODOLOGY AND CONCLUSION}

It is difficult to overestimate the value of the Wrights' experience in the design and fabrication of printing presses, bicycles and precision bicycle components when examining their work in aircraft. Simply generating a correct conceptualization of a working aircraft is of little worth without the means and ability to construct it. Building the first aircraft required the Wrights to rapidly develop models and prototypes. It also required the ability to repair damaged aircraft while in the field. Without these abilities it is very unlikely that they would have been the first successful aviators in spite of the fact that they had the most advanced understanding of aerodynamic theory in the world by 1903. Even if they hired expert fabricators and woodworkers to construct their designs for them, the difficulty of communicating to a worker how to conceptualize and build such a machine would have certainly generated miscommunications and prototypes that did not match what the Wright Brothers envisioned when they designed them. Delays caused by such problems would have at least delayed success, if it did not make it impossible all together.

Even so, as Crouch has identified, a much more varied background was needed in order to successfully build and fly the first aircraft than experience building and repairing bicycles. The Wright Brothers' work in aerodynamics was a math intensive endeavor that was aided greatly by the education received from their mother, Susan Koerner Wright, who possessed a strong background in mathematics. She, along with her boys' high school teachers, helped to teach Wilbur and Orville how to solve complicated algebra and trigonometry problems that represented objects in the real world. The Wright Brothers were confident enough in these abilities to literally bet their lives on the solutions. This 
was just one of many aspects of the Wrights' education that was critical to their success later.

However, building the first airplane took more than expert fabrication skills and a strong grasp of mathematics. There are a tremendous number of problems that develop in an undertaking this complex. In order to tackle these issues the ability to communicate ideas clearly, work as a team, and think through the problem solving process is one that they learned from their father. Bishop Milton Wright was a communicator by profession as well as a teacher. His example of pious self-discipline, humility, and studiousness was certainly emulated by his sons. These traits learned early in life paid big dividends during the Wright Brothers' work on aircraft and the way that they approached the problems that arose during design and testing.

These are just a few of the many examples of the massive amount of background preparation that the Wright Brothers needed in order to be successful in their aviation endeavors. Even though each experience was "rather insignificant in itself," when viewed together they paint a picture of two brothers that possessed an unusual, but special and varied background that made their success as the world's first aviators possible.

In this history I intend to review the events of the Wright Brothers' lives leading up to their first powered flight on December $17^{\text {th }} 1903$. This review will consist of a deep examination of their education, family life, and employment. Each of these aspects of their lives provided the Wright Brothers with specific skills that can be directly applied to the question, "How did the Wright Brothers learn to fly?" This examination will not spend a great deal of time on the aerodynamic research of the Wright Brothers as it has been extensively examined and written about by historians and engineers with far more 
expertise than I can bring to bear on the topic. However, this critical part of their work will not be overlooked and what connections exist between their earlier work in bicycles and their work in aerodynamics will be looked at in detail. Review of these experiences will be organized largely chronologically beginning with their childhood, then progressing to their entrepreneurial endeavors, before concluding with an analysis of the period between 1900 and 1903 when their time and money was heavily invested in aeronautical research and development.

In my search to better understand how these skills were developed, I examined numerous types of primary sources. Fortunately, the Wright Brothers and their family kept fastidious records of their lives. As a result there is a vast treasure-trove of documents and artifacts upon which to draw. ${ }^{20}$ However, the portion of their lives that I have focused on came before the brothers became internationally famous. As a result, the documentation of this time span represents just a fraction of the total historical record. Nevertheless, I had the pleasure of researching many different types of records of the Wright Brothers' activities in the early portion of their lives. These records include letters, journals, advertisements, school books, family books, report cards, newspapers, notes, sketch books, and business records. In addition to these there are the various aircraft, bicycles, bicycle components, machines, tools, and buildings that have been preserved as part of the historical record.

Each of these artifacts offers a different tool for the historian to utilize in the construction of a history. In this case many of the letters and journal documents provide

${ }^{20}$ These archives are numerous and include: The Wright State University Archives, The Dayton Public Library, Greenfield Village and The Benson Ford Research Center, Carillon Park in Dayton, Ohio, The National Museum of the U.S. Air Force at Wright-Paterson Field in Dayton, Ohio, The Franklin Institute in Philadelphia, The Smithsonian Air and Space Museum in Washington D.C., and the Library of Congress. 
insight into communications between Orville, Wilbur, and their family thereby helping to explain how they related to and taught each other. Family books serve to illustrate what the family knew and valued. School books and report cards offer a glimpse into what the brothers were formally taught and how well they learned in a classroom setting. Business records and advertisements are helpful in establishing what skills the brothers developed as entrepreneurs. Newspapers that the Wrights printed establish their fluency in skills such as writing, woodcarving, organization, and an ability to tolerate tedious jobs such as typesetting. The aircraft, bicycles, tools, and bicycle components establish in a very concrete way what skills the Wright Brothers were proficient in and help to illuminate where they may have gained inspiration for their aircraft designs and fabrication. ${ }^{21}$

I have visited many of the locations in which the Wright Brothers lived and worked in an effort to better understand the conditions surrounding the generation of their ideas that have since reshaped the world. These places at the very least served to provide me with a sense of scale of the environments in which the brothers operated. More importantly however, these locales gave me a sense of how the Wright Brothers physically accomplished what they did. The original machinery that they used has been preserved along with many of their tools. Examination of these artifacts gives a better idea of what it took to construct various projects and what skills were needed to successfully employ these tools.

${ }^{21}$ National Park Service reports on the Dayton sites and the Greenfield Village report on the West Third Street bike shop structure report offer outstanding sources for outlining what machines and tools were used at these locations. See: Quinn Evans, Historic Structure Report: The Wright Cycle Company Building (HS-01), (Dayton: Dayton Aviation Heritage National Historical Park, 1999); Mary Grassick, Historic Furnishings Report: The Wright Cycle Company Building, (Dayton: Dayton Aviation Heritage National Historical Park, 2007); Kathryn A. Keefer, The Wright Cycle Shop Historical Report, (Greenfield Village, Michigan: The Henry Ford, 2005). 
I believe that analysis of these primary sources will provide a new way to view the accomplishments of the Wright Brothers. By understanding how the brothers obtained their skills we can see that these seemingly natural born engineers gained their understanding in the same ways that all successful engineers do, through education and experience. I believe that what set the Wright Brothers apart was their ability to rapidly apply what they learned in ways that weren't immediately obvious. Because they utilized novel applications of skills developed from so many diverse disciplines, it can be difficult for a historian to adequately connect the dots. I believe that many of the connections between the Wright Brothers' work in previous professions and their work in aircraft became such an intimate and intuitive part of the Wright Brothers' thinking that it has gone unnoticed by historians and perhaps even by the Wright Brothers themselves. My goal is to utilize my personal experience in some of these activities, coupled with a more nuanced reading of the various documents and artifacts, to write a history on Orville and Wilbur Wright that is revealing in ways that previous histories have struggled to accomplish.

I intend to prove that it was not strange that two "bicycle mechanics," as they are often described, invented the first airplane. The Wright Brothers' background in bicycles and printing worked together with their education and family upbringing to develop a staggering engineering aptitude that served to guide them in answering a question and solving a problem and that had eluded humankind for millennia, "Is it possible to fly, and if so, how?" 


\section{CHAPTER 2}

\section{A SOCIAL CONTEXT FOR THE WRIGHT BROTHERS}

At first glance it appears that there was very little that Orville and Wilbur Wright held in common with the rest of America. The most glaring difference between them and most Americans was that they never married or were known to have maintained any significant romantic relationships in their lives. Beyond this there is the exceptional career path they chose. The sons of a Protestant bishop, they eschewed the ministry and instead worked in a number of different fields as entrepreneurs at a time when Americans tended to spend their entire careers in just one industry.

While the Wright brothers' lives were exceptional in many respects, in other ways they are quite representative of turn-of-the-century America. They were part of an American middle-class that was increasingly populated with journalists, engineers, mechanics, tinkerers, inventors, and entrepreneurs. Precision tools developed by the arms industry following the Civil War were reused to produce new consumer and industrial goods available in the marketplace. ${ }^{22}$ This expansion created new jobs assembling, operating, and servicing the machines that made the gilded age possible. As America became more industrialized, ideas for mechanical inventions flourished. This effect was clearly visible in the development of Dayton, Ohio; the Wright brothers' home town.

Dayton was an average sized American city at the turn-of-the-century; however its population had doubled between 1870 and 1880. This growth was fueled in part by the

${ }^{22}$ David A. Hounshell, From the American System to Mass Production 1800-1932: The Development of Manufacturing Technology in the United States, (Baltimore: The Johns Hopkins University Press, 1984), 189-190; Wiebe E. Bijker, Of Bicycles, Bakelites, and Bulbs: Toward a Theory of Sociotechnical Change, (Cambridge, Massachusetts: The MIT Press, 1995), 32. 
many industrial factories that increasingly filled the city's limits. The hundreds of machine shops, foundries, and factories in Dayton were busy making bicycles, cash registers, engine castings, railroad cars, and tools. In the wake of this industrial growth Dayton became the national leaders in patents filed per capita in 1890. This is not surprising however, as Dayton's per capita patent filings in 1870 were already fifth in the nation. ${ }^{23}$ The reason for this, contrary to popular accounts of born-genius inventors, is that invention does not occur in a vacuum. ${ }^{24}$ New ideas and technologies are typically built upon existing scientific principles or new applications of existing technologies. Put simply, invention begets invention.

Historian John H. Lienard, argues that invention is fueled by a "Zeitgeist." ${ }^{, 25}$ But the way this Zeitgeist functions is not quite as osmotic as it might appear. Most new technologies during this period were patented in order to provide the inventor with exclusive rights to produce the technology they patented. However, an interesting quirk of the patent process is that although patents protect inventors from unauthorized use of patented technology, they also provide public documents explaining the patented technology in detail. This disclosure requirement promotes a cross-pollination of ideas that allows inventors to build upon the creativity of each other. The Wright family seems to have been caught up in the excitement of the many new patent applications filed in

${ }^{23}$ Tom D. Crouch, "Introduction," in Honious, Ann. What Dreams We Have: The Wright Brothers and Their Hometown of Dayton, OH, (United States: Eastern National, 2003), 8.

${ }^{24}$ Thomas P. Hughes, American Genesis: A Century of Invention and Technological Enthusiasm, (New York: Viking Penguin, 1989), 8-52; Dean Keith Simonton, "Exceptional Creativity Across the Life Span: The Emergence and Manifestation of Creative Genius," In The International Handbook on Innovation, ed. by Larisa V. Shavinina, 293-308 (San Diego: Elsevier Science, 2003), 302; Jakab, Visions, xiv-xvi; Brooke Hindle, Emulation and Invention, (New York: New York University Press, 1981), passim.

${ }^{25} \mathrm{John}$ H. Lienard, How Invention Begins: Echos of Old Voices in the Rise of New Machines. New York: Oxford University Press, 2006), viii, 32, 96, 126, 133-134, 242. 
Dayton as Lorin Wright, one of Wilbur and Orville's older brothers filed a patent on a more efficient horse-driven hay bailing machine. ${ }^{26}$

By 1890, America's growing industrial capacity was applied to manufacturing a new type of bicycle with equal sized wheels and a chain-drive, dubbed the safety bicycle. The Wright brothers and much of America quickly developed a fascination with the safety bicycle that had been introduced to the American market in 1887 . The bicycle craze spawned an explosion in the number of new bicycle brands and retailers. In Dayton alone the number of bicycle shops went from five in 1891 to fourteen just two years later. ${ }^{27}$ As the Wright Brothers saw Americans flock to bicycle shops to buy the new machines, they responded by opening a bicycle repair shop of their own. Soon they were selling new bikes as well as repairing used ones.

Orville and Wilbur were much like many other Americans who were increasingly employed in industrial capacities as machinists and engineers. For example, in the 1890's the number of bicycle manufacturers in America grew from less than 30 in 1887 to more than 300 with a collective output of more than $1,000,000$ bicycles per year by $1897 .{ }^{28}$ During this time of two-wheeled enthusiasm the Wright brothers were working alongside the thousands of other men and women gainfully employed by the newly formed safety bicycle industry in America.

The machine shops, factories, and foundries that supplied the bike industry, among many others, became a critical part of the transition America made from the Victorian age to the twentieth century; and the Wright brothers worked on the front lines

\footnotetext{
${ }^{26}$ Lorin Wright Bailing Patent 1887, Wright State Archives, Wright Brothers Collection, series II, subseries 9 , box 6 , file.16.

${ }^{27}$ Crouch, Bishop's Boys, 109.

${ }^{28}$ Ibid, 106; Hounshell, 192.
} 
of this new industrial era. Factories that were making bicycles in the 1890's were later retooled to build the motorcycles and automobiles of the twentieth century. The improved roads built during the 1890 's that the bicycle craze initiated literally smoothed the transition between older horse drawn transportation and the automobile. ${ }^{29}$

Although the Wright brothers had a varied background of employment, they are best known as inventors. The Wrights, along with many other inventors during this period, conceived of new ideas and technologies that had a profound effect on society. While the brothers were unique in many ways, an examination of a few key American inventors during this period will show that the Wright brothers were not simply an anomaly.

Psychologist and prolific writer on the subject of innovative genius, Dean Keith Simonton has identified a number of traits that are common among this group. ${ }^{30} \mathrm{He}$ argues that innovative geniuses tend to come from homes where education and learning are highly valued and a large, diverse library is maintained. He also notes that highly innovative persons tend to be "omnivorous readers" of the books they have ready access to. Additionally, Simonton and other experts have identified that most inventors take part in a ten-year period of training and intensive practice within a particular field of study. ${ }^{31}$ However, he claims that this does not need to be formal training. On the contrary, he argues that statistics show extensive formal training appears to limit creative potential; therefore most inventors typically have received little of it. Lastly, because relationships and a life outside of the workshop or laboratory tend to interfere with the time available for invention, innovative geniuses are also more likely to remain single.

\footnotetext{
${ }^{29}$ Hounshell, 190, 214-215.

${ }^{30}$ Simonton, 293-308.

${ }^{31}$ Ibid, 295-296.
} 
Each of these characteristics accurately describes the Wright brothers. They never married, graduated from high school, or attended college. However, they worked in both the printing and bicycle industries for roughly ten years before they began to build airplanes. They both read intensively from the books available to them in their vast home library. However, Wilbur was especially well read with respect to mechanical, aeronautical, biological, historical, and legal topics among others. This broad based education allowed the Wright brothers to generate innovative ideas by applying principles gleaned from many different disciplines that were brought to bear on the problem of flight.

Other similarities can be found among inventors from this period. Famed inventors Thomas Edison, Reginald Fessenden, Hiram Maxim, Elmer Sperry, William Stanley, and Nikola Tesla all had a number of things in common with each other and the Wright brothers. None of them ever graduated from college. All of them were tinkerers at an early age. All of them initiated work on major inventions before reaching thirty years of age. Before each of them achieved success as inventors, they spent time working at diverse jobs in fields that were often unrelated to the one in which they became famous. ${ }^{32}$

The inventor from this list bearing the most striking similarities with the Wright brothers was Nikola Tesla. Also raised by a clergyman, Tesla decided to enter a technical school rather than the seminary before eventually dropping out at the technical school. Tesla also never married. Like Wilbur Wright, Tesla's childhood was marked by long periods of illness that confined him to his home. In Wilbur's case the time spent convalescing came after being struck in the face by a hockey stick as a teen. While recovering from this injury and caring for his mother's ailing health, Wilbur spent many

\footnotetext{
${ }^{32}$ Hughes, 16-17; Simonton, 298-299.
} 
hours, just as Tesla did during his childhood confinement, reading voraciously from books on a wide variety of subjects. ${ }^{33}$

Perhaps the most powerful correlation between the Wright brothers and the other inventors of their time was the universal desire to profit from their inventions. Alexander Graham Bell demonstrated earlier in the century that great wealth could be generated through profits derived from patented technology. Hoping to be a part of a new class of Americans made rich through patented inventions, the Wright brothers carefully protected the data that was critical to their success as aircraft engineers. ${ }^{34}$ To ensure their claim to aircraft technology, the patent they filed to protect their invention was worded broadly in its description of the technology. This was done with the hope that it would require anyone who built an aircraft of any kind to pay the Wright brothers for the opportunity to sell it. However, like many of the inventors of this period they found that patents were not always iron clad.

While inventors such as Edison and Maxim were able to profit greatly from their patents, many others did not, in spite of the high value of the technology they developed. Tesla saw huge profits for some of his inventions, but was defrauded of others. Edwin Armstrong found his valid claim on vacuum tube technology challenged in court only to lose his rights to an inventor that possessed greater legal savvy. ${ }^{35}$ In the case of some inventors, defending their patents in the courts at all became a losing proposition. This was the case for George Selden, whose patent of the automobile in 1895 was attacked

${ }^{33}$ Crouch, Bishop's Boys, 75-78; John J. O'Neill, Prodigal Genius: The Life of Nikola Tesla, (New York: Ives Washburn, 1944), 24, 31.

${ }^{34}$ Ibid, 230-232; Stephen B. Goddard, Race to the Sky: The Wright Brothers Versus the United States Government, (Jefferson, North Carolina: Wright and Wright, Papers \& Company, 2003), 119-120; C.R. Roseberrry, Glenn Curtiss: Pioneer of Flight. (Garden City, New York: Doubleday, 1972), 86-87.

${ }^{35}$ Hughes, 18-19. 
relentlessly in court by a rapidly growing number of automobile inventors until it was overturned in $1911 .^{36}$

The Wright brothers found themselves in a similar predicament. After years spent trying to defend their sweeping claims on the aircraft technology described in their 1906 patent, the Wright brothers found their creative abilities sapped. Meanwhile, other aircraft experimenters began to surpass the Wrights and developed aircraft that were faster, flew farther, and were easier to control. ${ }^{37}$ After Wilbur's death in 1912, Orville was so exhausted by this process that he sold the Wright Aircraft Company just three years later and did not see the wealth he had hoped for from his patent until $1917 .^{38}$

Orville and Wilbur developed their creative genius in similar ways as other inventors from this period. Inquisitiveness and independence led Wilbur and Orville to perform their studies outside the walls of the academy. Like other inventors, their formative years were spent experimenting with different careers and learning what they could from each of the jobs they held. After their initial success with aviation and securing a patent on the technology they developed, the Wright brothers found themselves disillusioned by the unfulfilled promise of guaranteed wealth offered by the patent process.

\footnotetext{
${ }^{36}$ Crouch, Bishop's Boys, 461-462; Goddard, 153, 184; Fred Howard, Wilbur and Orville: A Biography of the Wright Brothers, (New York: Alfred A. Knopf, 1987), 394.

${ }^{37}$ Roseberry, 189-198.

38 1917. "End Patent Wars of Aircraft Makers" New York Times, Aug 7; Howard, 196-208, 403409.
} 


\section{CHAPTER 3}

\section{THE EARLY YEARS: FAMILY AND PRINTING}

The Wright brothers' success can be traced back to a time before they had ever considered building aircraft, steerable kites, bicycles, or printing presses. Their upbringing and the development of their personalities significantly affected the way they conducted their experiments.

Milton and Suzan Wright's children in order of birth were Reuchlin, Lorin, Wilbur, Otis, Ida, Orville, and Katherine. Fraternal twins, Otis and Ida, died at birth. After being doted on by a mother who lost two children that were close in age to Wilbur and Orville, the two youngest boys developed limited social skills and a marked shyness. This tendency only intensified in Wilbur after he received a serious facial injury playing hockey. Both of the boys also suffered emotionally as they witnessed the declining health and eventual loss of their beloved mother to tuberculosis when Wilbur was twenty-three and Orville was just seventeen. ${ }^{39}$ In the wake of these events the brothers found themselves increasingly drawn together, allowing them to work as an extremely effective team. Never moving away from the home of their parents, they discussed their ideas long after the printing and bicycle shops had closed.

The intensities of their familial relationships also led them to place little sentimental value on the things that they built. Their first experimental kite made in 1899 was destroyed in 1905 while fully knowing that they had made history in 1903. Their first glider that they built in 1900 was abandoned in Kitty Hawk following testing. Parts of the 1901 glider were reused in the 1902 glider but Orville and Wilbur burned most of the

\footnotetext{
${ }^{39}$ Crouch, Bishop's Boys, 32, 38, 82-95.
} 
1901 glider to make room for the new machine. Following the successful tests of 1903 the Wrights ended up melting down their aluminum engine casing and recycling the material for use in their next larger engine. ${ }^{40}$ The engine and propellers from their 1904 airplane were saved for the 1905 airplane but the rest of it was burned. Their wind tunnel no longer exists, however the testing rig that was used inside of the wind tunnel was saved after being nearly forgotten as it sat in storage for about four decades. ${ }^{41}$ Orville and Wilbur's lack of sentimentality allowed them to quickly work through their experiments using each thing they built as a stepping stone paving the way for their next learning experience.

Education and learning were highly valued in the Wright home. Both of the Wright brothers' parents attended college. Their mother, Susan Wright, had a strong understanding of mathematics that she passed on to her children quite literally. Her algebra textbooks from her formal education remain in the Wright State University archives. $^{42}$ Wilbur and Orville's grades in math were typically A's and B's respectively. It appears that Orville's lower grades were due to his "medium" habits of application rather than any inability in the subject. ${ }^{43}$ Both brothers generated notebooks full of charts and tables containing the mathematical analysis of their aerodynamic testing. Although Wilbur and Orville never received high school diplomas, no one can doubt that they were good at math. This was likely due, in no small part, to the efforts of their mother.

\footnotetext{
${ }^{40}$ Wright and Wright, Papers, 1214.

${ }^{41}$ Ibid, 1183-1190; Jakab, 219-223.

${ }^{42}$ Susan Koerner's algebra textbook remains in the Wright State University Archives' Wright Brothers Collection Part I: The Technical Library. The book in question is: Charles Davies, Elementary Algebra: Embracing the First Principles of the Science, (Cincinnati: A.S. Barnes \& Co., 1954) and is autographed by Susan Koerner.

${ }^{43}$ Orville Wright, Central High School Report Card, Wright State University Archives, Wright Brothers Collection, Series II, subseries 6, box 6, file 3, 5.
} 
Their father Bishop Wright also had a profound effect on their approach to relationships and problem solving. While outgoing and friendly to peers and serving as a very loving father to his family, Bishop Wright's sermons often consisted of a stern call to repentance rather than meek invitations to lead a righteous life. ${ }^{44}$ Constant reminders to his family to improve their personal righteousness may have led to a negative approach to life's problems among his children. Wilbur wrote in 1903 that, "It is a characteristic of all our family to be able to see the weak points in anything, but this is not always a desirable quality as it makes us too conservative for successful business men, and limits our friendships to a very limited circle." ${ }^{45}$ The family’s drive toward perfection created a climate that was ideal at producing shyness and introspective problem solving, qualities that Wilbur and Orville had in spades.

Interestingly, Wilbur seemed to inherit his father's public speaking ability, but not his confidence. Wilbur was known to speak calmly and articulately to large audiences but was deeply reticent to display this skill owing to a conspicuous self-consciousness that seemed to define his life. ${ }^{46}$ Orville was also painfully shy. This shyness drove the brothers to interests that allowed them to work alone or with each other. Without this motivation it would have been much more difficult for the brothers to later find the time and focus for their work in aviation.

Despite his success in the bicycle business, Wilbur also seemed to be somewhat sheepish when it came to his occupational title of, "bicycle mechanic." In a letter to early aviation expert Octave Chanute, who wanted to publish some of the data Wilbur gathered from his experiments, Wilbur politely asked that his primary occupation remain secret

\footnotetext{
${ }^{44}$ Milton Wright, A Higher Moral and Spiritual Stand. Passim.

${ }^{45}$ Wright and Wright, Papers, 306.

${ }^{46}$ Ibid, 93, 95.
} 
"unless you are following the names of other experimenters with a similar reference." In an earlier letter to Chanute, Wilbur describes the wire used to truss their 1900 glider as "fifteen-gauge spring steel wire." ${ }^{48}$ While such wire may have been used for springs by someone in another industry, the Wrights knew this material as lightweight spoke wire. Orville later confirmed this fact in 1934 describing the truss wires they used as "spoke wire. ${ }^{, 49}$ Wilbur's subterfuge seems to be aimed at giving the impression that he and his younger brother were not merely mechanic tinkerers, but were professional engineers. Although Orville and Wilbur were confident in their abilities, they rightfully suspected that others would not feel the same way given their lack of formal credentials. Their selfconscious attitude provided them with greater motivation to prove their expertise by rapidly developing solid results from their aviation experiments.

This same shyness may have motivated the brothers to also avoid the academy, although they both loved to learn. After Wilbur finished all of the required work for his high school diploma, his family moved to another state before the proper paperwork for graduation could be completed. He never enrolled in any college program. Orville's school record was similar to that of his older brother. Orville's experimentation in printing at age sixteen with his high school friend Ed Sines left him itching to drop out of school in order to start his own printing business. A summer job at a print shop only intensified this desire and Orville eventually left Central High School during his senior year and never attended college.

Both brothers had actually been exposed to the printing industry long before they enrolled in high school however. Bishop Wright was an editor and contributor to the

\footnotetext{
${ }^{47}$ Ibid, 47.

${ }^{48}$ Ibid, 41 .

${ }^{49}$ Ibid, 1187.
} 
weekly Religious Telescope, the official paper of the United Brethren in Christ. When Bishop Wright was not away on church business he could often be found writing sermons to be published in the paper or working at the shop himself. Due to a schism that formed in the church over the popular decision to reverse the church's ban on membership in secret societies, Bishop Wright found himself publishing even more papers. He took the conservative position on the division and sought to maintain the church's ban on secret societies as it stood and published tracts to this end.

One of the first job printing contracts that Wilbur took part in with his younger brother was a pamphlet printed in 1888 describing a debate at a United Brethren meeting regarding the ban on secret societies. ${ }^{50}$ This pamphlet was printed using the job press that Wilbur and Orville fabricated from scrap parts. Unfortunately there are no surviving pictures or drawings of the press they built. All that remains is a list of some of the parts. These included the hinge from a folding buggy top, a tombstone, and a wood frame. ${ }^{51}$

Most Wright biographers relate the story of how a pressman from Chicago visited the Wright print shop and asked to see their press. When he was shown the machine in operation he exclaimed, "Well, it works, but I certainly don't see how it does the work." This is typically interpreted to mean that the Wright's press mechanism was so unusual that a professional pressman could not understand how it worked. This interpretation seems implausible however as a professional pressman should have no problem understanding how a small job press operated no matter how unusual it is. The pressman

\footnotetext{
${ }^{50}$ Wilbur Wright, Scenes in the Church Commission during the Last Day of its Session, (Wright Bros. Job Printers, 1888). Wright State University Archives, Wright Collection, Part II, Series II, Subseries 5, Box 5, File 4, Item 4.

${ }^{51}$ Howard, 6; Crouch, Bishop's Boys, 96.

52 Ibid, 96.
} 
was likely commenting on his amazement that a press made from scrap could work so effectively. In an hour the Wright press could crank out an astonishing 1000 pages! $^{53}$ In addition to the fabrication experience the printing business offered the Wright brothers, it also trained them to be precise, efficient, and methodical. Given the daily deadlines imposed by the various newspapers that the Wrights edited and published throughout the 1890's, they were forced to develop a systematic approach to their work that could ensure that deadlines were met. The skills developed by this experience aided in efforts to rapidly produce prototype aircraft as well as testing rigs that could be reset or repaired as quickly as possible. More evidence of the influence that printing had on their experimentation can be found in their highly organized records. The brothers' ability to repeat tests hundreds of times per day for years required a kind of patience that is either the result of insanity or intense practice over tens of thousands of hours. Over a decade of tedious daily typesetting gave the Wrights unrivalled patience and precision among early aviation experimenters.

Although most of the newspapers that the Wrights published seemed to flop, job printing contracts were their bread and butter, generating a respectable income. ${ }^{54}$ The Wrights invested the money this business produced into a second business venture they began in 1893, their bicycle shop.

\footnotetext{
53 Ibid, 96.

${ }^{54}$ Honious, 54.
} 


\section{CHAPTER 4}

\section{BICYCLES AND THEIR OFFSPRING}

There are few lives that are as well documented as those of the Wright brothers. But even with this overwhelming abundance of primary source material, there continues to be a gap in the existing historiography. Literally dozens of historians and engineers have spent decades examining the aircraft testing methods used by the Wright brothers. Models of their aircraft have been tested in wind tunnels in order to better understand how their aircraft worked. The actual aircraft they built have been dissected, scrutinized, and cataloged. Full size replicas of the aircraft were made many times over. Yet with all of this intensive study of how the Wright brothers learned to fly we still have just a portion of the answer. We know how they developed aerodynamic theories and how these theories were tested, but there is little understanding of how they learned to build aircraft. Moreover, few historians have asked how the Wrights developed an ability to produce radically new ideas on human flight.

Perhaps the clearest example of this disconnected view of the Wright brothers' lives is offered by Ann Honious and Peter Jakab. Both historians note that a key difference between the Wright brothers and other experimenters was that they evolved their aircraft designs. They used the same basic configuration of a biplane with a forward canard in all of their early experimental aircraft rather than "[jumping] from one completely different design to another." 55 But why did they do this? What drove the Wright brothers to develop their aircraft so differently than everyone else? Neither asks

${ }^{55}$ Jakab, 102-103; Honious, 111; Wright and Wright, Papers, 54; Tom D. Crouch and Peter L. Jakab. The Wright Brothers and the Invention of the Aerial Age, (Washington D.C.: National Geographic, 2003), 57. 
this question in their monographs. If the Wrights' evolutionary approach was so important to their success, then why is there no examination of the factors that influenced this decision? If these questions go unasked then the Wright brothers mistakenly retain their position in history as born geniuses that possessed an instinctive intellectual advantage over their competitors.

I believe that the answer to why the Wright brothers evolved their aircraft designs lies in a basic examination of the day-to-day work the Wright brothers performed as bicycle frame builders. Like the overwhelming majority of bicycle frame builders, the Wright brothers evolved the designs of their bicycles. All of their men's frames maintained the same basic shape but varied slightly in size according to the customer's needs. It is quite common for a custom frame builder to adjust the geometry of the frame or the type of tubing used in its construction in order to balance considerations of weight, strength, price, fit, and ride quality. It is clear that the Wright brothers did this as they developed different bicycle models at different price points, weights, and sizes. Even so, all of their bikes maintained the same basic shape and used the same construction techniques. ${ }^{56}$ The bicycle industry as a whole continued this evolution of the brazed steel bicycle frame and fork well into the 1980's until aluminum frames came into vogue and began to replace their traditional ferrous counterparts. It is no surprise then that the Wright brothers applied this same technique to building airplanes.

The Wright's foray into the bicycle business began as they took interest in the sport themselves. Orville, the more impetuous of the two, spent $\$ 160$ in 1892 on a new

${ }^{56}$ Fisk and Todd, 30-35. This was also true of their forks as they offered different fork crown and tubing options. Their hubs also evolved as they offered fixed-gear hubs first, before later developing coaster brake hubs. 
Columbia racing bike at a time when most Americans made only $\$ 400$ a year. ${ }^{57}$ The fact that he spent so much money on the machine shows how passionate he was about cycling. The more conservative brother Wilbur soon followed and purchased a used racing bike of the same make for half the price. Orville often raced at the local YMCA's oval track and experienced a good deal of success, finishing on the podium at least three times.

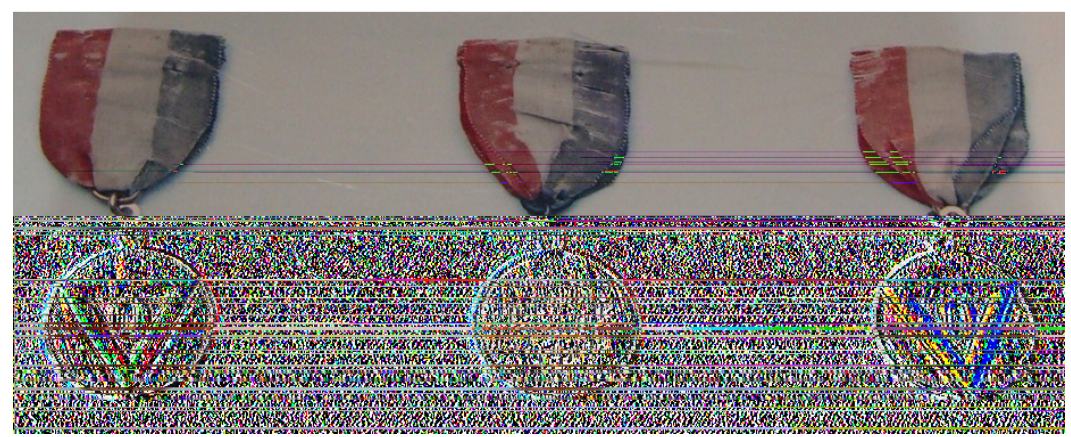

Figure 2: Orville Wright bicycle racing medals.

Examples of medals won by Orville on display at Carillon Park in Dayton, Ohio. Photo by author.

Interestingly, the athleticism that the Wright brothers developed through cycling became critical to their success as aviators. While it is true that piloting a glider for less than thirty seconds per flight requires little physical exertion, hauling that same glider up a sand dune hundreds of times, does. In a remarkable display of their physical prowess, Orville and Wilbur performed over 250 glides in just two days at Kitty Hawk in $1902 .{ }^{58}$

${ }^{57}$ Crouch, Bishop's Boys, 105. Corrected for inflation, Orville's Columbia would have cost well over $\$ 3500$ today.

${ }^{58}$ Wright and Wright, Papers 280. 


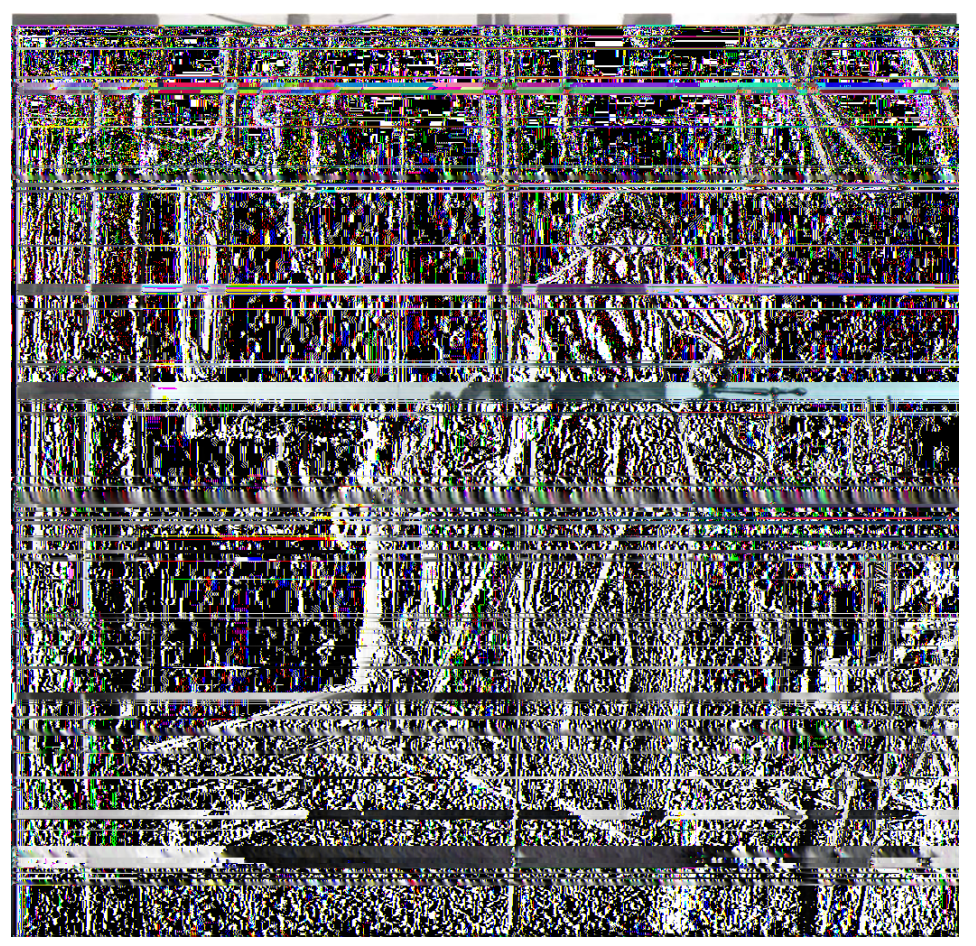

Figure 3: Orville at the lathe.

This picture of Orville working at the lathe in the bike shop reveals a classic bicycle racer's physique, a thin frame with legs that are comparatively larger than his upper body. Orville was 5'8" tall and 140lbs. ${ }^{59}$ Photo courtesy of Wright State University.

Beyond the physical strength that Wrights developed through cycling, Orville's racing experiences in 1892 likely taught him the value of aerodynamic drafting. ${ }^{60}$ These experiences may have piqued an interest in aerodynamics that he and his brother later explored in greater depth. In 1900 during the Wrights' initial aerodynamic theory development, a letter written by Wilbur describes how he tested and calculated the aerodynamic drag created by a cyclist riding at a given speed. ${ }^{61}$ There is nothing in the letter explaining that the test occurred shortly before the letter was written. It is possible

\footnotetext{
${ }^{59}$ Wright and Wright, Papers, 80; Fred C. Kelly, The Wright Brothers: A Biography Authorized by Orville Wright, (New York: Harcourt, Brace and Company, 1943), 8.

${ }^{60}$ Riding closely behind a competitor that shields the following rider from the wind greatly reduces the amount of effort required by a cyclist to maintain a given speed.

${ }^{61}$ Wright and Wright, Papers, 49-50
} 
that this experiment was done much earlier as an exercise meant to satisfy an avid cyclist's curious mind.

Just a year after the brothers each purchased their first safety bicycles they opened a bike shop together. This new entrepreneurial effort was spurred by constant requests from friends to repair their bicycles, proving that the Wrights were already somewhat proficient as bicycle mechanics prior to this time. ${ }^{62}$ After the summer of 1893 the brothers' bike shop was so successful that it produced more revenue than the printing business that they started five years earlier and operated concurrently. ${ }^{63}$

However, just a year and a half later Wilbur became disenchanted with his new bicycle business, even though he appears to have been the driving force behind starting it. ${ }^{64}$ Displaying his constant thirst for new knowledge, he wrote a letter to his father in September 1894 lamenting that his personality was not "specially fitted for success in any commercial pursuit" and that he intended to quit working at the bike shop and enroll in college. ${ }^{65}$ Although his father offered to loan Wilbur tuition money, Wilbur never took him up the offer.

This decision seems to have puzzled Wright brothers historians Tom Crouch, Peter Jakab, and Ann Honious. Crouch wrote of Wilbur's decision:

Wilbur did not pursue his father's offer, nor, so far as we know, did he ever raise the issue of college again. He may have felt he was too old. He would certainly have been reluctant to ask Orville to accept full responsibility for their joint enterprises. Whatever the reason, he decided to redouble his efforts to make the bicycle shop a success. ${ }^{66}$

\footnotetext{
${ }^{62}$ Crouch, Bishop's Boys, 107.

${ }^{63}$ Ibid, 109.

${ }^{64}$ Ibid, 107-109; Honious, 87.

${ }^{65}$ Crouch, Bishop's Boys, 110. While the letter did not specify this, Yale was the school Wilbur

${ }^{66}$ Ibid, 110.
} was referring to. 
Jakab's equally confusing analysis of Wilbur's decision concludes that, "Both Wilbur and Orville were becoming a bit restless, and they began to contemplate a new outlet for their inquisitiveness. As the world knows, they chose the airplane." ${ }^{167}$ Yet, with this conclusion, Jakab offers no explanation as to why Wilbur reversed his decision to attend college in 1894. Moreover, by Jakab's own admission Wilbur did not seem truly interested in flight experimentation until at least 1896 and did not seriously research the subject until $1899 .{ }^{68}$ Honious is entirely silent on the matter, offering no reason at all for Wilbur's reversal of decision. ${ }^{69}$

In order to understand Wilbur's decision to stay with the bicycle business rather than enroll in college courses, an understanding of his motivation is required first. Wilbur's desire to go to college was more firmly rooted in his passion for learning rather than in his disdain for business. It is likely that Wilbur never went to college because he found a new skill to learn that maintained his interest and made him more money.

It was just a month later in October 1894 when Orville wrote to his father and explained that he and his brother were planning to begin building their own bicycle frames and custom built bicycles. ${ }^{70}$ The Wrights had of course made this decision at least a couple of weeks before writing this letter. Just planning out their designs and which tools and parts were needed to make the frames and proprietary components could have easily taken that long. This time can then be added to the time required to finance, order, ship, and deliver the required tools and parts and it is not unreasonable to expect that the Wright brothers began to seriously think about building their own bicycles only days

\footnotetext{
${ }^{67}$ Jakab, 40.

68 Ibid, 41.

${ }^{69}$ Honious, 87-88.

${ }^{70}$ Crouch, Bishop's Boys, 111.
} 
after Wilbur wrote to his father to tell him he was abandoning the bicycle shop for the academy. He likely made the decision to stay at the bike shop before his father even had time to respond in writing. Wilbur never quit the bicycle business in the fall of 1894 because he was content to learn how to build his own bicycles from the ground up in lieu of a college education.

Bicycle frame building is not the kind of occupation that is learned over a weekend. Like any frame builder past or present, it took time for the brothers to develop this skill and the challenge of it must have excited these two inquisitive bicycle mechanics. These skills include: how to cut and miter steel tubing, designing and building jigs to hold the tubing in place as it is brazed together, and manipulating the torch to properly heat the tubing and draw the filler material to the right places. Performing each of these tasks correctly could mean the difference between the life and death of a customer. A poorly constructed frame or fork can result in the front wheel catastrophically separating from the rest of the bicycle causing the rider to make a grizzly face-first impact with the ground. Needless to say, there was more than just money riding on the Wright brothers' proficiency in this new project. The proud craftsmen did not disappoint however, and there seems to be no record of any failures since their bikes were first introduced to the market in April of 1895. The brothers claimed that they would unreservedly "guarantee" the quality of their machines. Their top quality bikes were braded "Van Cleve" in honor of their ancestors by the same name that settled the Dayton Valley. Hence their advertisements that contained the tagline, "Van Cleves get there First." 71

\footnotetext{
${ }^{71}$ Ibid, 113; Fisk and Todd, 28, 30.
} 
All Van Cleve bicycles came with hand built wheels containing a Wrightdesigned hub at the center. Their Van Cleve hubs incorporated an oil-bath lubrication system and a locking bearing adjustment feature that was sure to keep amateur mechanics happy. The Wrights claimed that their hub was "dust proof" and that "one oiling every two years is all they require." 72 To sweeten the deal the hubs came with built-in replacement bearing cones that served double duty as locknuts. With these additional cones the Wrights claimed that this extended the life of the hub to six years. A unique coaster brake hub was also developed by the Wrights and machined by local machinist Charlie Taylor who later came to work for the Wrights. The precision processes employed to design and build the high quality Van Cleve frames and hubs provided the Wright brothers with not only a satisfying intellectual challenge, but also taught them the skills they later used to build their aircraft.

In order to construct their line of bicycles, the Wright brothers acquired a number of machine tools that became part of a light machine shop in the back room of bicycle store. These tools included a drill press, turret lathe, and saws. ${ }^{73}$ To power them the Wrights assembled a one-cylinder engine that ran on natural gas. The engine was connected to a Wright-designed line shaft system that transferred the power from the engine to the machines. Building this shop not only gave them the tools that they later needed to build their aircraft, it taught them how to use the tools proficiently. Also, designing the shop engine gave them a stronger working knowledge of internal combustion engines that they later used designing the engine for their 1903 flyer.

\footnotetext{
${ }^{72}$ Fisk and Todd, 30.

${ }^{73}$ Keefer, Wright Cycle Shop Historical Report.
} 
In 1896 when the Wright brothers received word of German aviation experimenter Otto Lilienthal's death in a gliding accident they began to investigate the subject of human flight in greater depth. Wilbur read the work of Sir George Cayley, Alphonse Penaud, Étienne-Jules Marey, among other engineering books and articles on human aviation as well as bird flight. After he had consumed all of the information on the subject that was available to him locally, he contacted the Smithsonian institute in 1899 to obtain any other aviation literature that existed. In his typical self-conscious fashion, Wilbur explained in his letter to the Smithsonian that he was, "an enthusiast, but not a crank in the sense that I have some pet theories as to the proper construction of a flying machine."74 Perhaps this was further evidence of the insecurity Wilbur felt as a "bicycle mechanic" entering a world of trained engineers.

Unbeknownst to Wilbur, around this same time in a bike shop just a few hundred miles away in Hammondsport, New York another bicycle mechanic was working away unaware of Wilbur Wright's insecurities or his interest in aviation. Nevertheless, this Hammondsport bicycle mechanic later crossed paths with Wilbur and his younger brother before eventually becoming their nemesis. After a brief but successful stint as a junior professional bicycle racer, Glenn Curtiss opened a bicycle shop of his own in 1900. Curtiss also started his own brand of bicycles, but paid a contractor to build them. This business decision was not an indicator of a lack of mechanical ability however, as Curtiss soon began building small gasoline motors and attaching them to his bicycles in 1901. Curtiss's success with motorcycles motivated him to abandon the bicycle business and sell motorcycles exclusively by $1902 .{ }^{75}$ He eventually became a member of the team that

\footnotetext{
${ }^{74}$ Wright and Wright, Papers, 4-5.

${ }^{75}$ Roseberry, 11-21.
} 
set out to not only destroy the Wright brothers' claims of priority, but also the patent rights to the aircraft technology that they developed. By 1909, Curtiss also surpassed the Wright brothers' aircraft world speed record and helped turn one of the Wrights' greatest allies against them in the process. ${ }^{76}$ Although they were bitter competitors, Curtiss's success helps to demonstrate that the training and experience that he and the Wright brothers received as bicycle racers and mechanics developed skills and abilities that had a significant effect on their future as aeronautical engineers.

${ }^{76}$ Ibid, 189-198. 


\section{CHAPTER 5}

\section{TAKING TO THE AIR}

When the Wright brothers began to seriously research heavier-than-air human flight in 1899, the problem looked as if it could be solved relatively easily. The Wrights assumed that Lilienthal was on track to be the first successful powered airplane pilot before his death in 1896. Believing that Lilienthal's failure was the result of poor testing procedures and inadequate safety considerations, the Wrights concluded that addressing these issues would ensure success. ${ }^{77}$ It appeared that Lilienthal had already determined the most effective wing shapes by virtue of his extensive testing, careful data collection, and his two-thousand successful glides. All that was required for success was to obtain Lilienthal's data and begin constructing a prototype aircraft. ${ }^{78}$

At the core of the safety issue the Wrights identified was the need for flight training; a difficult prospect when dealing with a vehicle unlike any that existed before it. Although Lilienthal successfully completed over two thousand flights, the total time he spent in the air amounted to just five hours spread out over years of testing. In reference to this, Wilbur quipped that "even Methuselah could never have become an expert stenographer with one hour per year for practice.",79

While the Wrights were new to flying, they could apply the balance and athletic skill they developed through years of recreational cycling and racing to control an

${ }^{77}$ Wright and Wright, Papers, 62.

${ }^{78}$ To this end, Wilbur wrote a letter to the Smithsonian Institute asking for copies of whatever published information on human flight was available. Wilbur also began corresponding with Octave Chanute, a civil engineer located in Chicago. After a successful career engineering bridges, Chanute was now in semi-retirement and pursuing his true passion, human flight. He had compiled nearly all of the available documentation on the subject that existed up to that point and had become a human encyclopedia on the subject. In May of 1900, Chanute began to serve as a free consultant to the Wrights and as a sounding board for the brothers to bounce ideas off of. Wright and Wright, Papers, 4-5.

${ }^{79}$ Ibid, 15-17. 
airplane. However, even with this background, learning to fly would result in at least as many crashes as they experienced when they first learned to balance on two wheels. Moreover, the consequences for error while flying were much greater than when learning to ride a bicycle, so a learning method that limited the likelihood and severity of crashes was needed.

The solution to this problem was to practice flight through the use of kites. By making a kite large enough to carry a man, the Wright brothers hoped that they could practice gliding just a few feet into the air at a ground speed of zero. ${ }^{80} \mathrm{~A}$ kite held the promise of allowing the brothers to gain more flight time in a matter of days than Lilienthal had accrued in years, all while operating in perfectly safe conditions. Once they had mastered flying manned kites, they would transition to untethered gliding, followed by powered flight testing.

This testing strategy represented one half of the Wrights' plan for safety. The other half was to design a safer aircraft. In order to protect the pilot in case of a nose first impact with the ground (the type of impact that killed Otto Lilienthal and Percy Pilcher) the Wrights decided to place the elevators ${ }^{*}$ in front of the wings instead of at the tail of the aircraft. With this arrangement the aircraft would maintain a more level attitude in the event of a stall, helping the Wrights to avoid ever making a potentially deadly nose-first impact with the ground. ${ }^{81} \mathrm{~A}$ second benefit of this design was that the front portion of the

\footnotetext{
${ }^{80}$ Ibid, 26.

* The Wright brothers referred to this control surface as a "rudder," although they are called "elevators" today when placed at the tail of the aircraft. Elevators are small horizontal control surfaces or wings usually located at the tail of an aircraft that are designed to provide pitch control. When this same type of control surface is placed at the front of the aircraft, as it was on the Wright brothers' early aircraft, it is referred to as a "canard" today.

${ }^{81}$ Howard S. Wolko, "Structural Design of the 1903 Wright Flyer," in The Wright Flyer: An Engineering Perspective, ed. Howard S. Wolko, 97-106 (Washington D.C.: Smithsonian Institution Press, 1987), 98.
} 
aircraft was designed to crumple upon meeting a hard impact with the ground and could thereby protect the pilot lying on the wing in the event of a crash. ${ }^{82}$

Their plan also included a radical improvement to Lilienthal's aircraft designs that had the glaring problem of poor roll control. In reality, Lilienthal's glider had no significant aerodynamic roll control to speak of because it relied entirely on the pilot shifting his weight to one side or the other in order to roll the aircraft along its longitudinal axis. This ineffective means of changing direction also offered little help in counteracting crosswinds. Wilbur learned through observation that birds maintained roll control partially by shifting their body weight but mostly by twisting their wings to alter the angle of their wingtips. ${ }^{83}$ Through this means, birds are able to increase the lift on one wing relative to the other which results in one of the wings rising while the other falls, resulting in an aerodynamically controlled roll. Such a design applied to a manned aircraft promised to give the pilot a greater ability to maintain level flight when buffeted by a crosswind. ${ }^{84}$ This technology was at the heart of the Wrights' first aircraft patent and it represented perhaps the greatest difference between their aircraft designs and those of their competitors. ${ }^{85}$ The discovery was so critical to the development of modern flight that variations of this system are still in use today on nearly every aircraft in the world.

However, the prevailing aerodynamic theory in the 1890's assumed that using aerodynamic control surfaces meant to maintain stability in flight would be overly complicated and far too difficult to use. An unstable aircraft designed to use such controls required constant correction in all three axes of movement in order to maintain straight

\footnotetext{
${ }^{82}$ Wright and Wright, Papers, 61-63.

${ }^{83}$ Ibid, 35, 44.

${ }^{84}$ Ibid, 327.

${ }^{85}$ United States Patent No. 821,393.
} 
and level flight. In light of this complicated control issue, early aviation pioneers believed that an aircraft needed to have a design that produced automatic stability. With such a design, it was imagined that an aircraft would operate much like a boat floating on water. While this worked for lighter-than-air flying machines such as balloons and zeppelins, heavier-than-air machines required a different solution. This was a concept that, while foreign to many of their contemporaries, was intuitive to the Wrights as a result of their experience with bicycles. ${ }^{86}$

Perhaps the best example of this inability to understand the need for aerodynamic control surfaces comes from French aviation experimenter Ferdinand Ferber. After learning of the Wrights success with their wing warping control mechanism and how it was assembled, Ferber still decided against using it, laconically stating "I did not wish to employ it in 1902, as I judged it useless to begin with..."87 As avid cyclists and professional bicycle frame builders, the Wright brothers understood from experience that aircraft control could not exist without some instability with respect to roll. A key reason that two wheeled vehicles can stay upright is due to a certain amount of instability designed into them. This allows a rider to lean and steer the bike in order to balance the machine or change direction.

The inspiration for a mechanism that could manipulate the wings to produce a bird-like twisting action came to Wilbur while working in the bike shop in July $1899 .{ }^{88}$ While holding an empty bicycle inner tube box in his hands he began to idly twist it while holding onto the open ends of the box. Wilbur soon realized that the opposing sides of the box remained parallel when twisted, yet one corner could be raised above another

\footnotetext{
${ }^{86}$ Crouch, Bishop's Boys, 234.

${ }^{87}$ Ibid, 232..

${ }^{88}$ Wright and Wright, Papers, 8.
} 
without compromising the structure of the box. The same idea was applied to manipulating the biplane wings on a kite that they constructed in the summer of 1899 . This new technology was referred to as "wing warping." After completing some initial experiments with small handheld kites designed to test the viability of wing warping as a means of roll control, the Wrights were confident that they could apply the same design principles to larger kites that could carry a man aloft. ${ }^{89}$ The same kites could then be untethered and used as gliders for more advanced testing. The next summer the Wrights began construction of their first full scale glider in the backroom of their bike shop.

In May of 1900 Wilbur began corresponding with Octave Chanute, a civil engineer located in Chicago. ${ }^{90}$ After a successful career engineering bridges, Chanute was now in semi-retirement and pursuing his true passion, human flight. He compiled nearly all of the available documentation on the subject that existed up to that point and was a human encyclopedia on the subject. ${ }^{91}$ Chanute acted as a free consultant to the Wrights and a sounding board for the brothers to bounce ideas off of.

Wilbur highly valued Chanute's opinions; but he never took Chanute's advice to be the undisputed truth. In a letter to Wilbur, Chanute was critical of the Wrights' decision to perform initial tests using a man-carrying kite claiming that he had tried one before and it was more trouble than it was worth. ${ }^{92}$ The brothers took note of the

${ }^{89}$ Wright and Wright, Papers, Plate 14.

${ }^{90}$ Ibid, 15.

${ }^{91}$ National Air and Space Museum, Otto Lilienthal and Octave Chanute: Pioneers of Gliding, (Washington D.C.: Smithsonian Institution, 1980); See Octave Chanute's collection of early aviation experimentation originally published in 1894 for examples of Chanute's recordkeeping: Octave Chanute, Progress in Flying Machines, (Long Beach: Lorenz \& Herweg, 1976).

${ }^{92}$ Wright and Wright, Papers, 20-21. 
objection but confidently continued with their original plan believing that safety and flight training should be their top priorities. ${ }^{93}$

Wilbur and Chanute also disagreed over the amount of aerodynamic drag that was generated by the body of a pilot seated upright verses lying prone. Cycling came into play here in a critical way. Using his training in algebra and geometry, Wilbur tested and then calculated the amount of horsepower a bicycle rider generated to overcome aerodynamic drag while traveling a certain distance in a fixed amount of time. Working backward Wilbur was able to solve for the drag coefficient of the rider and arrived at a figure that matched the drag calculated on the Wrights' experimental airfoils. ${ }^{94}$ This figure differed from the one calculated by Lilienthal and Chanute. Confident in his work, Wilbur boldly wrote to Chanute that it was possible that the Lilienthal tables could be incorrect and that Chanute measured the wind speed in his experiments incorrectly. ${ }^{95}$ After a few letters back and forth between the men, Chanute dropped the argument as it was clear that Wilbur's testing calculations were correct.

One piece of advice from Chanute that Wilbur did take to heart was his suggestion that their flight testing be conducted over water or sand in order to provide greater safety for the pilot. ${ }^{96}$ In order to locate a suitable location to test their aircraft, Wilbur contacted the Weather Bureau to determine which location could offer the most consistent wind. Of the many options available, they chose Kitty Hawk, North Carolina

${ }^{93}$ Wright and Wright, Papers, 62.

${ }^{94}$ Ibid, 45-50.

${ }^{95}$ Ibid, 48. Wilbur also wrote that it was possible that his calculations did not match Lilienthal's because he may have incorrectly estimated the area of the rider's body. Wilbur also admitted that it was also possible that the porous nature of the fabric used as the skin for his airfoils was throwing off the numbers.

${ }^{96}$ Ibid, 20-21. 
because it offered not only consistent wind, but miles of sand dunes that could be safely glided off of. The Wrights travelled there in September of 1900 to begin testing their kite.

Initial tests were quite positive although they did not yield the extended tethered flight times the Wrights predicted. Much of this was due to an underestimation of the variability in wind that they experienced at Kitty Hawk. ${ }^{97}$ Even so, the Wrights were able to demonstrate that the aircraft was controllable and that their wing warping system worked on this larger scale just as it did on the small scale experiments. Perhaps more importantly, the limited time spent by the brothers flying the kite gave them enough flight experience that they were able to each make a few safe, untethered glides. Orville and Wilbur chalked up any failures to inaccurate construction methods and resolved to reengineer their wings to more closely copy the profiles called out by Lilienthal thereby reducing the drag caused by the design of the wing's structural components (ie. leading edge supports, ribs, etc.). ${ }^{98}$ The Wright brothers went home to Dayton energized believing that they could take what they learned and improve upon this glider over the winter and return to Kitty Hawk the next year.

The improvements made on the second generation glider included an adjusted wing camber for increased lift and a revised wing structure for reduced drag. This glider was also significantly larger with a wing area nearly double the size of the 1900 glider. The Wrights believed that the increased lift that the larger wings generated would lengthen flight times and improve control. ${ }^{99}$

However, initial kite tests in Kitty Hawk during August of 1901 were discouraging. Utilizing their intensive study of aerodynamic theory over the past two

\footnotetext{
${ }^{97}$ Ibid, 29.

${ }^{98}$ Wright and Wright, Papers, 41,78-79.

${ }^{99}$ Ibid, 99-118.
} 
years, and a mathematic analysis of the forces at play, they quickly determined that something was wrong. Utilizing a scale attached to their kite ropes, the Wrights were able to measure the aerodynamic drag of the aircraft. This measurement showed that the kite did not produce the lift-to-drag ratio promised by the Lilienthal tables. Confused, they assumed that their wing did not match the profile prescribed by the German.

Nevertheless, they continued testing with the aircraft they had. The Wrights were able to achieve manned flight aboard the machine in kite form and made some successful untethered glides, but this model was harder to control than the glider they had tested the year before. ${ }^{100}$ To make matters worse the dunes of Kitty Hawk were infested with mosquitoes to the point that they darkened the sky, making living conditions miserable. In short, the whole experience was frustrating. At the end of the tests Wilbur dejectedly remarked to Orville, "Not within a thousand years would man ever fly!"101

${ }^{100}$ Crouch, Bishop's Boys, 209-213.

${ }^{101}$ Ibid, 213. 


\section{CHAPTER 6}

\section{THE TURNING POINT}

The Wrights returned to Dayton convinced that the lift tables generated by Lilienthal were in error. This realization brought the brothers to an important crossroads. Without accurate lift data, the Wrights would be forced to start from scratch and generate their own tables if they wanted to continue with their experiments. This meant developing more sophisticated aerodynamic testing tools and spending hundreds of hours fabricating and testing the experimental airfoils.

When faced with this monumental task they could have simply waited for Chanute, Langley, and others to come up with the correct figures and then try again. Or, they could have just given up all together and focused all of their time on the bicycle business. Yet, they decided against the easy route. Why? The answer to this question lies in a review of their past.

The Wright brothers were given their family's support and encouragement throughout each of the various careers they tried. When Wilbur decided against entering the ministry, as his father had, and instead joined in Orville's printing business, his parents were encouraging. ${ }^{102}$ Bishop Wright was also supportive of his sons' decision to enter the bicycle trade. ${ }^{103}$ Years later when Wilbur wrote to his father that he was considering leaving the bicycle business to pursue a teaching career, his father supported him just as he always had and even offered to loan him money for tuition. ${ }^{104}$ Their sister Katherine was willing to work at the bike shop when her brothers were away testing their

\footnotetext{
${ }^{102}$ Crouch, Bishop's Boys, 94-96.

${ }^{103}$ Ibid, 109.

${ }^{104}$ Ibid, 110.
} 
aircraft and wrote encouraging letters to them while they were away. ${ }^{105}$ With this unwavering support, there was no reason for Wilbur and Orville to believe that their family would not continue to offer encouragement toward their work in airplanes.

With respect to their business endeavors the Wright brothers accomplished seemingly every goal that they set for themselves. They started a successful printing business quite literally from scratch by fabricating their own printing press. They successfully owned and operated not only a retail bicycle shop, but also designed and manufactured their own custom bicycles. As if that were not enough, they also developed their own line of bicycle components that incorporated numerous innovations. If they could be successful in each of these challenges, why would they think that they could not decipher the laws of aerodynamics?

Taking into account the career changes made by the Wrights, and their study of still more subjects in their free time, it is clear that they had a love of learning. It was this curiosity that they demonstrated their whole lives that helped to motivate them to continue on with their testing. The new learning opportunities that would be available to them as professional aircraft designers must have inspired the brothers to continue with their aerodynamic testing. ${ }^{106}$

Lastly, there may have been a feeling of personal calling expressed by the Wrights that they were meant to be the ones who would unravel the mystery of human flight. Orville's remark, "Isn't it astonishing that all these secrets have been preserved for

\footnotetext{
${ }^{105}$ Wright and Wright, Papers, 27, 57, 69-70, 92.

106 This curiosity is evident in Orville's tinkering with homemade adding machines, early automobiles, and the many other projects that occupied his free time while working at the bike shop. See: Crouch, Bishop's Boys, 110-111, 114.
} 
so many years just so that we could discover them!!" suggests that this is the case. ${ }^{107} \mathrm{~A}$ piece of paper used as a marker placed between the pages of the Book of Revelation in one of the family copies of the New Testament bears a citation for chapter five, verse ten. This verse refers to the believers who were to be crowned as "kings and priests" that "shall reign on the earth" at the time of the second coming. Such a marking, one of only two in that bible, suggests that this doctrine may have been emphasized in the Wright home. ${ }^{108}$ Perhaps this exaltation might take the form of mastery over increasingly potent technologies such as flight? This speculation aside, the belief in the Wright home that a higher power was watching over them is certainly evident. Such a belief seems to have given the Wrights confidence to accomplish their goals even when they were faced with difficult challenges.

In order to determine why Lilienthal's lift tables were flawed, the Wright brothers began to more closely examine how he gathered his data. One of the biggest problems the Wrights uncovered was the way that Lilienthal recorded wind speed. ${ }^{109}$ However, inaccuracies in wind data could not account for the extent of the deviation in lift figures that the Wrights recorded compared to those of Lilienthal. The Wrights suspected that Lilienthal's lift data was skewed by the lift coefficient (.005) used to calculate the lift of his airfoils. ${ }^{110}$ This coefficient was also used to take into account the amount of

${ }^{107}$ Wright and Wright, Papers, 310-315, 313.

${ }^{108}$ Wright State University Archives, Wright Brothers Collection, Box 2 item 11, MS-1 1877.

${ }^{109}$ Wright and Wright, Papers, 132. Lilienthal had misunderstood the limitations of the instruments he was using to record his wind data. The instrument in question was Lilienthal's anemometer. As an anemometer records a gust of wind, it begins to spin at a faster rate. This in turn increases centrifugal force within the instrument, which causes it to continue to spin at a high rate even after the wind subsides, resulting in a reading that is too high. Lilienthal did not correct for this instrumentation problem which resulted in inaccurate lift and drag figures for the wing shapes he tested.

${ }^{110}$ Ibid, 120-122; Jakab, xviii. Jakab notes that although Wilbur believed that Lilienthal was using the Smeaton coefficient to calculate his lift tables (see Wright and Wright, Papers, 120-121), Lilienthal had in fact used his own lift coefficient derived from his own testing. 
aerodynamic drag in an airfoil. Given the realization that Lilienthal's wind data was in error, it only followed that his lift coefficient needed to be checked as well. Moreover, Langley determined a significantly lower drag coefficient figure (.0032) that seemed to be more in line with what the Wrights experienced in their testing. ${ }^{111}$

In order to more conclusively determine where the error was stemming from, the Wright brothers needed to fabricate an aerodynamic testing rig. Knowing from experience that a bicycle rider must overcome aerodynamic drag when pedaling down the road, they realized that they could simulate the effect of a constant wind on a stationary object by placing the object in question on a bicycle and then riding it at a constant speed on a windless day. It naturally followed that the Wrights utilized a bicycle to develop what we might describe today as, "a crude wind tunnel."

${ }^{111}$ Wright and Wright, Papers, 121. 


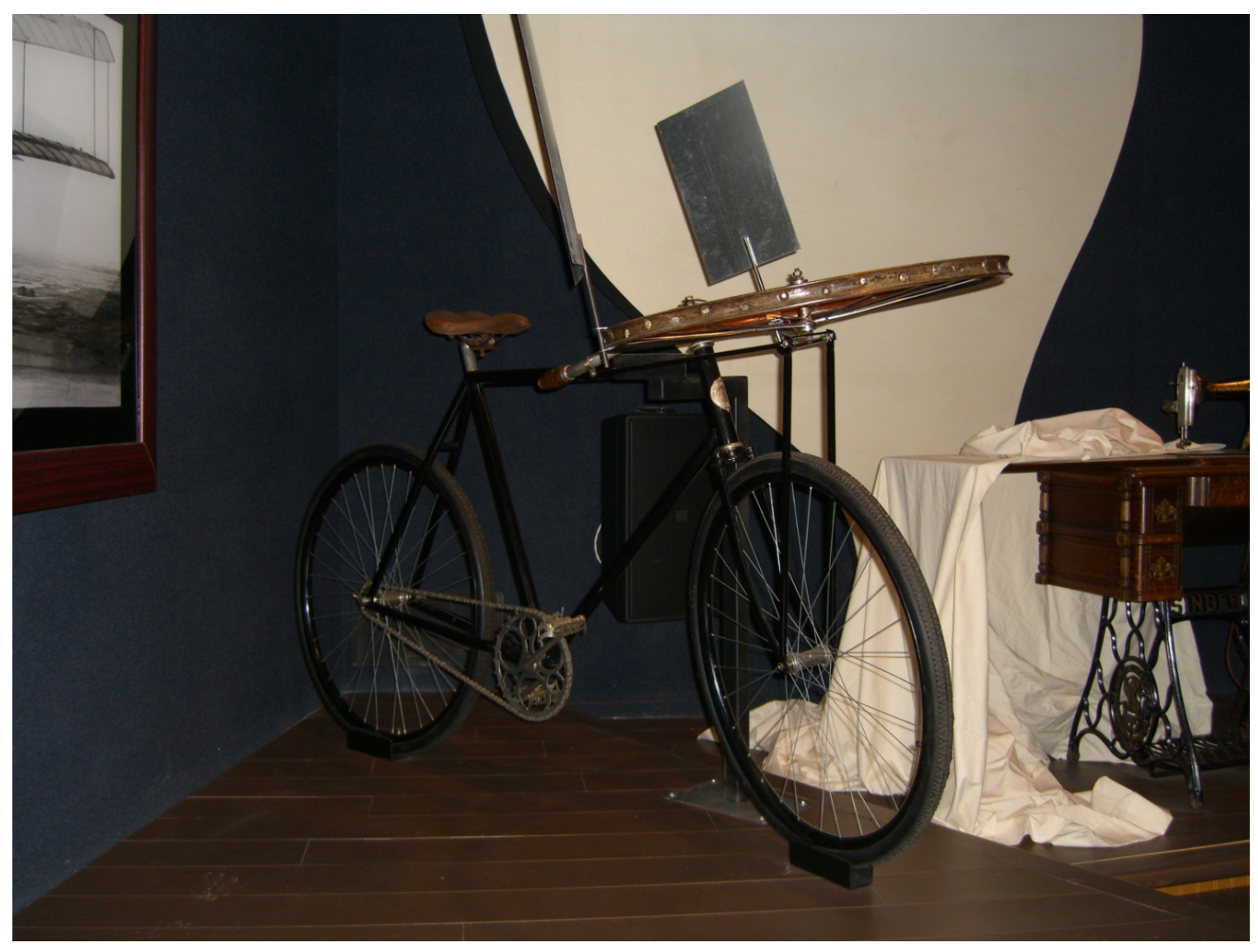

Figure 4: The Wright brothers' first airfoil testing rig.

Early Wright wind tunnel test bicycle replica built added to an authentic Van Cleve bicycle at Carillon Park in Dayton, Ohio. Photo by author.

In late September of 1901, using their expertise as bicycle mechanics, the Wrights took a spare wheel and mounted it horizontally on a structure that they fabricated and fastened to the handlebars and front axle of a bicycle. Attached to the rim of the wheel was a rectangular piece of sheet metal measuring 8 " by 18 " that was parallel to the spokes. This sheet metal was supposed to generate an amount of drag that Lilienthal's tables claimed was equal to the amount of drag created by an 8 " by 12 " piece of sheet metal bent into a Lilienthal airfoil shape. This airfoil was then attached to the rim in a position that should balance the drag of the two pieces of sheet metal. If the drag 
coefficient was correct, the wheel would not turn as Wilbur pedaled down the road on a windless day. If it was incorrect and the wheel turned, he could adjust the size of the sheet metal until the drag of the two shapes balanced and prevented the wheel from turning. ${ }^{112}$ The resulting area of the metal used to produce the drag could then provide Wilbur with the figures needed to calculate the correct drag coefficient of the airfoil.

The crude wind tunnel worked and definitively proved that the Lilienthal tables were in error. However, the Wrights understood that the mass of the rim and the drag of the hub bearings reduced the sensitivity and precision of the rig. ${ }^{113}$ Additionally, there was the imprecision caused by momentary crosswinds that could potentially influence the data. To eliminate this imprecision the Wrights built a true wind tunnel in their shop with model airfoils that could be tested through the use of a balancing scale made mostly from spokes and discarded hacksaw blades. The data that this wind tunnel produced was instrumental in the Wright brothers' success. They tested hundreds of airfoil shapes in their wind tunnel over the winter of $1901 / 1902 .{ }^{114}$ The data they collected was used to produce improved wing shapes that were incorporated into their next prototype aircraft, a larger glider that the Wrights built and tested at the end of the summer of 1902.

The Wright brothers' wind tunnel testing rig was very simple. To the casual observer it might appear to be simply cobbled together. However, a closer examination of it reveals its precision. ${ }^{115}$ Moreover, the principles guiding its design reveal the influence of their past work in other fields.

\footnotetext{
${ }^{112}$ See plate "Y" in appendix for a picture of the bicycle wind tunnel testing rig.

${ }^{113}$ Wright and Wright, Papers, 123-124.

${ }^{114}$ Ibid, 135-230.

${ }^{115}$ Ibid, 206-207, plate 30, 31, 32; Crouch, Bishop's Boys, 226-228.
} 
The minimalist nature of the testing rig was clearly designed to obtain meaningful data as quickly as possible. Producing a speedy setup for repetitive tasks was something that the Wright brothers were extremely familiar with in their experience as machinists. The old adage that "time is money" rings especially true in this industry. The more time a machine is down while it is being set up, means fewer parts can be made in a given time, leading to higher prices per part. In order for the Wrights' bicycle components and frames to be affordable they needed to develop processes that allowed them to rapidly generate their wares.

The same is true in printing. Once the type for a page is arranged and locked up in a frame, making additional copies is very inexpensive. This idiosyncrasy of the nineteenth century printing industry pushed typesetters to work extremely fast without sacrificing accuracy. If one takes into account that the Wrights made their own presses from scratch, it becomes even clearer that they must have been sensitive to the need for developing a tool that could get a job done quickly and accurately with limited setup time.

The accuracy of the wind tunnel data partially depended on it having as little friction between the moving parts as possible. Any bicycle racer looking for an edge on the competition does their best to reduce bearing friction to a minimum through careful cleaning, lubrication, and adjusting of their hub and crank bearings. As professional mechanics, as well as hub and crank manufacturers, the Wright brothers were daily working to reduce this friction to a minimum and this experience could have influenced the design of their simple wind tunnel testing rig. 
Bicycle frame building experience that taught them how to quickly and accurately shape, carve, and braze steel. This skill was also useful in their wind tunnel testing and sped up the process of making test airfoils. Wilbur nonchalantly wrote to George Spratt that he could "easily" make his own test airfoils from steel. "With a pair of tin shears, a hammer, a file, and a soldering iron you can get almost any shape you want." ${ }^{, 16}$ Perhaps ironically, this advice was included in a letter after a passage in which Wilbur tried to reassure Spratt during a period of self-doubt. However, Spratt's "blues" came from the realization that the Wright brothers clearly possessed far greater mechanical skills than he did. Wilbur politely denied the charge writing that Spratt's insecurities were all in his "imagination." ${ }^{117}$ Later, addressing the same insecurity, Wilbur explained to Spratt, "what you take for some special quality of mind is merely facility arising from constant practice, and you could do as well or better with like practice."118

The Wright brothers' method of getting the job done quickly and simply, without over engineering, was a hallmark of their work developing aircraft. It was this speed and efficiency that allowed them to beat competitors such as Langley that were working on the same goal for much longer and with budgets as much as seventy times larger than the Wright brothers' ${ }^{119}$ Wilbur and Orville were not just fabricators, they were not just scientists, they were not just mechanics or machinists; they were all of these things. Even more amazing is that each brother possessed much of the same skills as the other, meaning that they both could understand and apply the principles they discovered rather than being wholly reliant on the other in one area or another. This resulted in an

\footnotetext{
${ }^{116}$ Wright and Wright, Papers, 208.

${ }^{117}$ Ibid, 205.

118 Ibid, 306.

${ }^{119}$ Howard, 123.
} 
incredible amount of engineering acumen and experience that could be applied to the problem of human flight. These qualities made the Wright Brothers far more efficient and effective engineers than their competition.

Other early aviation engineers often relied on others to produce their aircraft. Those who did not tended to have little practical experience in fabricating strong, lightweight structures and their aircraft suffered as a result. Some men also physically suffered for this inexperience when their faulty aircraft tumbled out of the sky, impacted the ground and shattered their bodies.

After Otto Lilienthal's two thousand successful flights, a design flaw in his glider led to his death in August of $1896 .{ }^{120}$ Although Lilienthal was a trained engineer specializing in steam engines, his inexperience in understanding material strength limits or the forces acting upon his aircraft may have killed him. On his final flight a gust of wind violently pitched the craft's nose upward. Lilienthal tried to regain control by pushing the elevator control down hard. The stop for the elevator failed and caused the elevator to become locked in this position. At the same time the aircraft stalled. After this, the nose quickly pitched downward as the glider fell out of the sky before the locked elevator forced the glider partially inverted and impacted the ground. Lilienthal's body struck the earth with such velocity that it fractured his spine, ending his life the following day. ${ }^{121}$

Percy Pilcher suffered the same fate, in a similar aircraft just four years later. However, in Pilcher's case, his aircraft broke up in midflight before plummeting out of

\footnotetext{
${ }^{120}$ Wright and Wright, Papers, 15-17, 75, 102.

${ }^{121}$ National Air and Space Museum, Otto Lilienthal and Octave Chanute: Pioneers of Gliding, (Washington D.C.: Smithsonian Institution, 1980).
} 
the sky. ${ }^{122}$ Pilcher was not deficient in fabrication ability however. He worked as a shipbuilder's apprentice for over a decade before his fatal flight. Even so, this experience did not provide him with the engineering experience required to develop an aircraft that was sufficiently light and strong.

Samuel Langley possessed impeccable engineering credentials and served as the Chair of Mathematics for the United States Naval Academy, and later as the Secretary of the Smithsonian Institution. While working as the Secretary of the Smithsonian he developed his first aircraft which he named the "Aerodrome." This experimental aircraft had four large wings attached to a slender fuselage which made it resemble a large dragonfly. The machine was designed to take off from the roof of a houseboat with the aid of a catapult. On its second manned and powered launch, the Aerodrome immediately pitched vertically after being released from the catapult. Simultaneously the aft wings failed catastrophically at their roots folding upward until the two wingtips nearly touched each other. The broken dragonfly then fell out of the sky and sunk into the Potomac River just a few feet off of the bow of the boat. ${ }^{123}$ The development of the Aerodrome cost a total of $\$ 70,000$ (in 1898 dollars), $\$ 50,000$ of which was obtained from the U.S. Government. The remaining $\$ 20,000$ was contributed by The Smithsonian. ${ }^{124}$ Its construction was performed by skilled craftsmen and overseen by engineer Charles Manly. Yet, even with all of the money and credentials behind the Aerodrome, it was a spectacular failure.

${ }^{122}$ Wright and Wright, Papers, 102.

${ }^{123}$ Crouch, Bishop's Boys, 262. The first flight did not see a structural failure, but ended nevertheless with a watery crash into the Potomac just a few feet off the bow of the launching boat.

${ }^{124}$ Ibid, 257; Howard, 123. 
Octave Chanute utilized his vast understanding of aerodynamic theory to design an experimental glider that he hoped he could add an engine to later. Lacking the time or ability to build such a machine, he employed Edward Huffaker to build the machine for him. Working almost entirely unsupervised, Chanute was dismayed when he was shown the completed project. The pasteboard tubing used to form the structure of the glider was so flimsy that Chanute did not believe that it would survive a single flight. ${ }^{125}$ Chanute turned out to be wrong, as the craft did fly successfully, however the pasteboard airframe crumbled in a rainstorm while at Kitty Hawk for testing in $1901 .{ }^{126}$ Wilbur Wright thought the whole experiment was so ill-conceived that it was "a joke."127

The next year Chanute partnered with Charles H. Lamson and Augustus M. Herring to produce two more aircraft. Both Lamson and Herring had built many gliders over the previous six years. However, both produced gliders that were so poorly constructed they had no possible chance of flying in even ideal conditions. ${ }^{128}$ The Lamson machine could only get off the ground as a kite in a thirty mile per hour wind. Wilbur Wright witnessed the testing and wrote that the wings were constructed so badly that they sagged and twisted under their own weight. Herring's machine was a failure as well. While this glider was more structurally sound than the Lamson glider, the design collaboration between Chanute and Herring resulted in a craft that met neither of the men's goals. ${ }^{129}$

Each of these aviation pioneers and their assistants lacked a strong practical knowledge of the structural limits of the materials they were using, and an understanding

\footnotetext{
${ }^{125}$ Wright and Wright, Papers, 57.

${ }^{126}$ Ibid, Plate 25.

${ }^{127}$ Ibid, 118-119.

${ }^{128}$ Crouch, Bishop's Boys, 233.

${ }^{129}$ Ibid, 239.
} 
of the physical forces an aircraft needed to endure in flight. As the scientists, engineers, and fabricators of their machine, the Wright brothers were able to combine these specialized skills in a synergistic way that produced sturdy, smartly engineered aircraft. I believe that understanding the true depth of this connection is often given little consideration by historians. I suspect that this is because only a few components of the Wrights' 1903 flyer used tubular steel construction similar to bicycle frames. The rest of their aircraft were made from wood. Such analysis does not take into account that the Wright brothers had an extensive practical understanding of the capabilities of wood used in high stress structural applications. This understanding came from assembling hundreds of wood structures capable of withstanding thousands of pounds of pressure applied to them at all times while withstanding an additional cyclical load of hundreds of pounds applied millions of times during the lifespan of the structure all while weighing just a few pounds. The structure to which I refer is the humble bicycle wheel consisting of a steel hub and spokes, laced to a wooden rim.

During the mid 1890's wood rims were increasingly popular amongst avid cyclists for the smoother, more damped ride quality they offered compared to the steel rims they replaced. Always the competitive businessmen, the Wrights' offered customers a choice of rim materials used in the custom bicycles purchased from them. ${ }^{130}$ These rims were of course laced to the steel Van Cleve hubs that the brothers designed themselves. Each of the thirty six spokes used in one of these wheels was likely hand tensioned to over a hundred pounds per spoke. ${ }^{131}$ Personally hand-building hundreds of these wheels

${ }^{130}$ Fisk and Todd, 35.

${ }^{131}$ There is a general consensus among wheel builders using modern wood rims that 120-170 pounds of spoke tension is ideal. The Wrights likely used similar tensions as the standard spoke diameters used in the 1890's are still in use today. 
gave the Wright brothers a working understanding of how strong a properly designed wood structure could be.

While many different species of wood were used by the bicycle industry during this time, there is no consensus regarding which species was used in the rims sold by the Wrights. In fact, the subject does not even come up in the dozens of existing histories on the Wright brothers. However, I believe that this experience was critical to their understanding of how to build a strong and light aircraft that could not only handle the stresses of flight, but also the many rough landings their experimental aircraft were put through. 


\section{CHAPTER 7}

\section{ON TRACK FOR SUCCESS}

The Wright brothers returned to Kitty Hawk at the end of August 1902 and spent over three weeks testing their latest glider. Like the gliders of years past, this machine also utilized a few bicycle parts in some key structural areas. The ribs and spars of the wings were lashed together with cord that was normally used to sew tubular bicycle tires together. ${ }^{132}$ The Wrights knew from experience that this was inexpensive yet extremely strong. It was so strong that just a few strands could withstand over one hundred pounds per square inch of pressure applied to it when used in a typical bicycle tire. Wheel spokes were again used to cross-brace the wing spars for lateral stability. ${ }^{133}$ The Wrights could have chosen a different material such as a woven steel cable, but their familiarity with spokes and the massive loads they were capable of handling, offered a strong, cheap, readily available material. Their long experience with such materials likely helped them to get into the sky much quicker than competitors that lacked this experience.

The 1902 glider had new wings which were shorter front to back (high aspect ratio wing) in order to produce greater lift and was the first Wright aircraft to have a tail assembly of any kind. The five foot tall fixed twin vertical rudders on the tail were intended to solve a control problem discovered in their 1901 glider that was caused by their "wing warping" roll control system. The unequal drag between the two wings, that occurred when the wings were warped, caused the nose of the aircraft to yaw in the opposite direction that the aircraft rolled toward. This meant that if the pilot rolled left,

\footnotetext{
${ }^{132}$ Wright and Wright, Papers, 1185-1186.

${ }^{133}$ Ibid, 41, 1187.
} 
the nose simultaneously drifted to the right causing a loss of control referred to as adverse yaw. Orville and Wilbur designed the tail rudders to stabilize the yaw of the aircraft during rolls and thereby counteract this phenomenon. ${ }^{134}$

However, the rudders stabilized the glider to the point that once a turn was initiated, the aircraft could not be controlled back to a wings level attitude, invariably ending the flight in a crash. To solve this new problem, the Wrights made modifications to the glider in the field and eliminated one of the tail rudders and setup the remaining one to automatically move in tandem with the wing warping controls. This change made coordinated turning possible allowing the brothers to control both roll and yaw together automatically. ${ }^{135}$

The new control system closely resembles the method of control used to turn bicycles. To make a controlled turn on a bicycle, the rider leans the bike to one side while simultaneously turning the front wheel in the same direction. When a bicycle is leaned to one side, the front wheel will essentially turn automatically due to the geometry of the head tube (steering column of the bicycle) and the forward offset (or rake) of the fork. To illustrate how this principle works, simply stand next to a bicycle and hold onto the saddle in order to keep the bike vertical. Now push the saddle to one side or the other and you will see the handlebars naturally turn in the direction the bike is leaning. The amount the handlebars turn in such a demonstration is the precise angle required to perform a safe and controlled turn at that lean angle. This design aspect makes riding a bicycle without holding onto the handlebars possible. The Wright brothers' experience as cyclists and

\footnotetext{
${ }^{134}$ Ibid, 269, Crouch, Bishop's Boys, 238.

${ }^{135}$ Crouch, Bishop's Boys, 238-239.
} 
frame builders may have influenced their decision to incorporate a coordinated control system into the 1902 machine.

When the new control system was combined with the larger wings of the 1902 glider, the Wright brothers were able to set new records for gliding. Their longest time in continuous flight was now twenty-six seconds. Another flight produced a record distance travelled at 622.5 feet. These flights represented just two of the estimated seven hundred to one thousand glides the Wrights made that year in Kitty Hawk. ${ }^{136}$ Orville announced in a final letter to his sister before returning home that, "we now hold all the records!",137 Returning home triumphant on Halloween night 1902, the brothers were confident that they could achieve powered flight the next year.

Sticking to the original plan to keep the entire process as simple as possible the Wrights sent out letters in December to at least ten gasoline engine manufacturers in order to locate an engine to power their next prototype. ${ }^{138}$ After receiving responses that no engines were available that met their power-to-weight specifications the Wrights dropped the idea confident that they could make an engine themselves. By January 1903 they were already building a new engine of their own design.

The Wright brothers' self-confidence throughout their engine building endeavor is staggering. Rather than devising a simple one-cylinder engine as they had built previously to power their shop tools, their new aircraft engine had four cylinders housed in an aluminum case. Some experts on early gasoline burning engines point to the Wright engine as perhaps the first aluminum gasoline engine ever made. ${ }^{139}$ Although this new

\footnotetext{
${ }^{136}$ Wright and Wright, Papers, 279-280, 325; Crouch, Bishop's Boys, 240-241.

${ }^{137}$ Wright and Wright, Papers, 280.

${ }^{138}$ Ibid, 286-287.

${ }^{139}$ Ibid, 1210-1214.
} 
and unproven alloy was being applied in such a complicated and powerful machine, the Wright brothers were not simply rolling the dice hoping that the light weight alloy was strong enough for the job. They tested the tensile strength of the alloy first, and then calculated how much material was needed to withstand the forces that they determined would be placed upon it. ${ }^{140}$ Beyond this testing, their confidence seems to have originated solely in their experience building their shop engines and all of the many other mechanical fabrication experiences they had in the past.

Years of working in fields that required economy of effort such as printing, bicycle frame building, and machining trained the Wrights to find quick, simple solutions to engineering problems. Like other aspects of the Wrights' flight testing protocol, their engine was made just good enough to get the job done, and nothing more. It was primitive even by the standards of the day. ${ }^{141}$ The engine had no carburetor to mix the fuel and air coming into the cylinders. Instead, the engine was designed to vaporize the gasoline as it came in contact with the hot metal in the cylinder head before being sucked into the combustion chamber. The cooling system was equally primitive. While it did possess a water jacket and radiator, there was no water pump to circulate cool water toward the engine which led to overheating after running for just a few minutes. The goal was to simply prove that the aircraft design worked. The quickest way to achieve this goal was to make an engine that could be machined rapidly and was light, simple, and easy to repair. For the pragmatic Wright brothers more advanced engines with higher horsepower and greater endurance could wait until the next prototype.

\footnotetext{
${ }^{140}$ Ibid, 1212.

${ }^{141}$ Crouch and Jakab, 116.
} 
Expert machinist and Wright Cycle Company employee Charlie Taylor performed the necessary work to machine the engine, completing it in just six weeks time.

Disappointingly, initial tests resulted in a total failure when a crank bearing seized after gasoline leaked into the bearing and contaminated it. ${ }^{142}$ This did not deter the brothers however as they simply pressed on, salvaged the components they could and built another engine of the same design. ${ }^{143}$

The Wright brothers' approach to powering their aircraft contrasted greatly with the plans of Langley and his larger, much better funded team. Langley's assistant Charles Manly developed a radical new radial engine configuration that was especially well suited to aviation applications. Manly's engine was far larger and more complicated but it produced nearly five times as much horsepower and a much higher power-to-weight ratio than the Wright engine. ${ }^{144}$ Unfortunately for Langley, this power could not be fully translated into increased thrust due to an inefficient propeller design.

The Wright brothers on the other hand used their wind tunnel to develop remarkably efficient propeller designs. While these designs were radical for their time, they closely resemble propellers used to this day. ${ }^{145}$ Their improved design allowed them to efficiently apply the lower power produced by their small engine toward propelling their aircraft. Wind tunnel testing proved that a propeller is simply a rotary wing. Determining the shape of the propeller was simply a matter of applying a wing shape that efficiently produced lift at the air speed encountered at any given point along the length of the propeller while spining at a given rate of revolutions per minute.

\footnotetext{
${ }^{142}$ Ibid, 298-299.

${ }^{143}$ Ibid, 307.

${ }^{144}$ Crouch, Bishop's Boys, 257.

${ }^{145}$ Wright and Wright, Papers, 313.
} 
To carve the propeller shape dictated by the wind tunnel testing, Orville and Wilbur did what they had done at nearly every step of the way along the road to their eventual success; they reapplied the skill sets that they developed earlier in life. Orville studied woodcutting as a teenager and honed this skill through years of work spent carving the blocks of wood that became the illustrations in his printing jobs. ${ }^{146}$ Wilbur however, had even more practical experience in this realm. Close friend Ed Ellis described weeks long camping trips spent with Wilbur in the mid 1890's that involved rowing a canoe that Wilbur built himself. Ellis noted in his telling of the story that Wilbur was quite proud of the canoe he made. ${ }^{147}$ Doubtlessly this experience building the canoe must have taught Wilbur much about carving long pieces of wood precisely into flowing shapes much like the propellers he made a few years later.

After completing their propellers in the late spring of 1903 the brothers continued working to construct their next prototype aircraft. Over the next few months the airframe was constructed in the back of the Wright Cycle Company shop. Many of the parts of this aircraft were originally made for use on a bicycle. The supports for the propeller shafts were partially constructed from lightweight steel tubing that was normally used for bicycle frames. The brazing method used for joining the tubing was similar to bicycles and utilized gusseting that resembled bicycle frame lugs. ${ }^{148}$

\footnotetext{
${ }^{146}$ Wright State University Archives, Wright Collection, Part II, Series II, Subseries 8, Box 6, File 12.

${ }^{147}$ Crouch, Bishop's Boys, 116.

${ }^{148} \mathrm{See}$ plate $\mathrm{X}$ in the appendix for comparison of the joints used in the Wright flyer compared to a standard bicycle frame.
} 

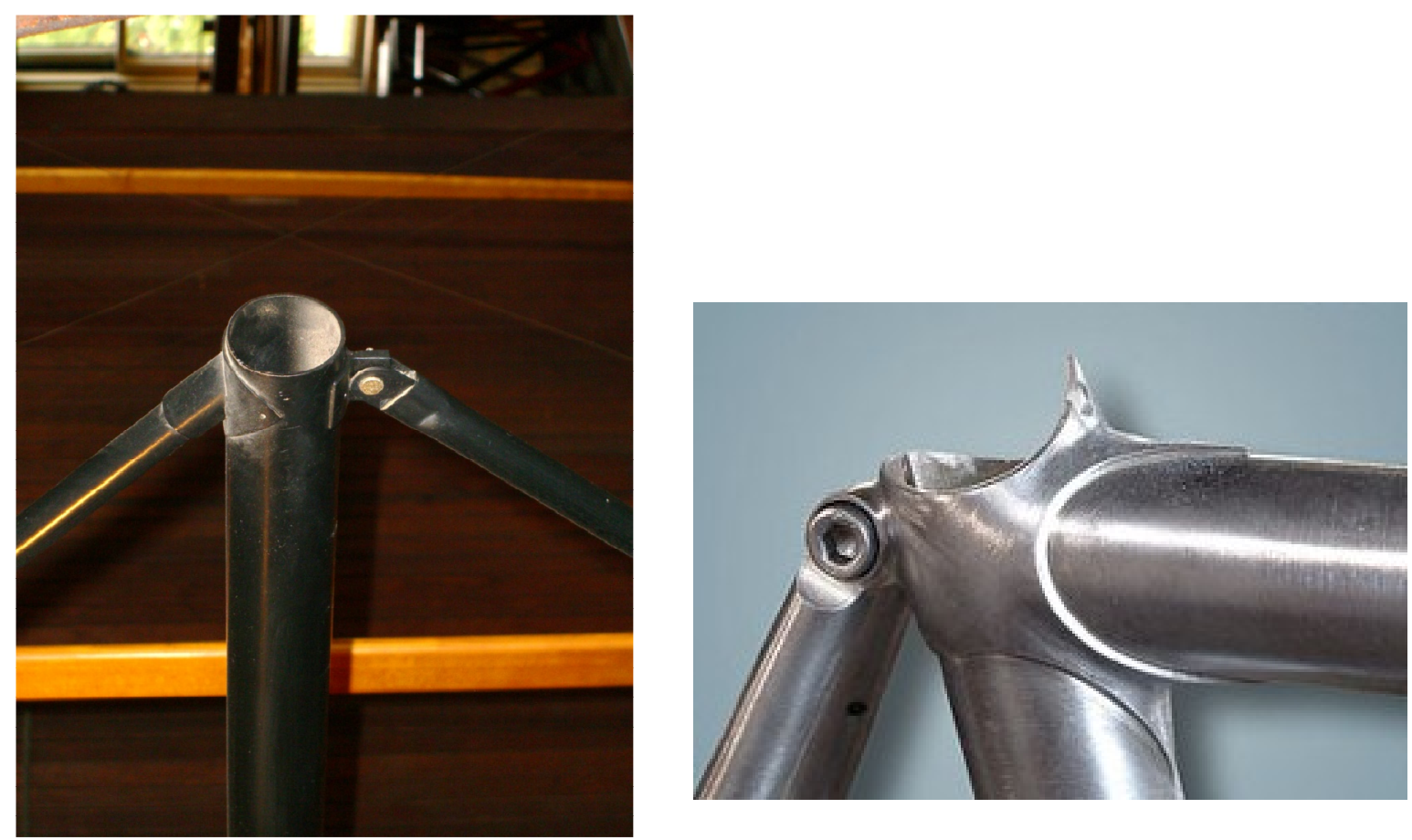

Figure 5: Lugged Construction.

Similar lugged joint construction on a replica of the 1903 Wright Flyer propeller shaft housing (left) to that of a bicycle pictured at right. Photo at left taken by author at Greenfield Village in Dearborn, Michigan. 

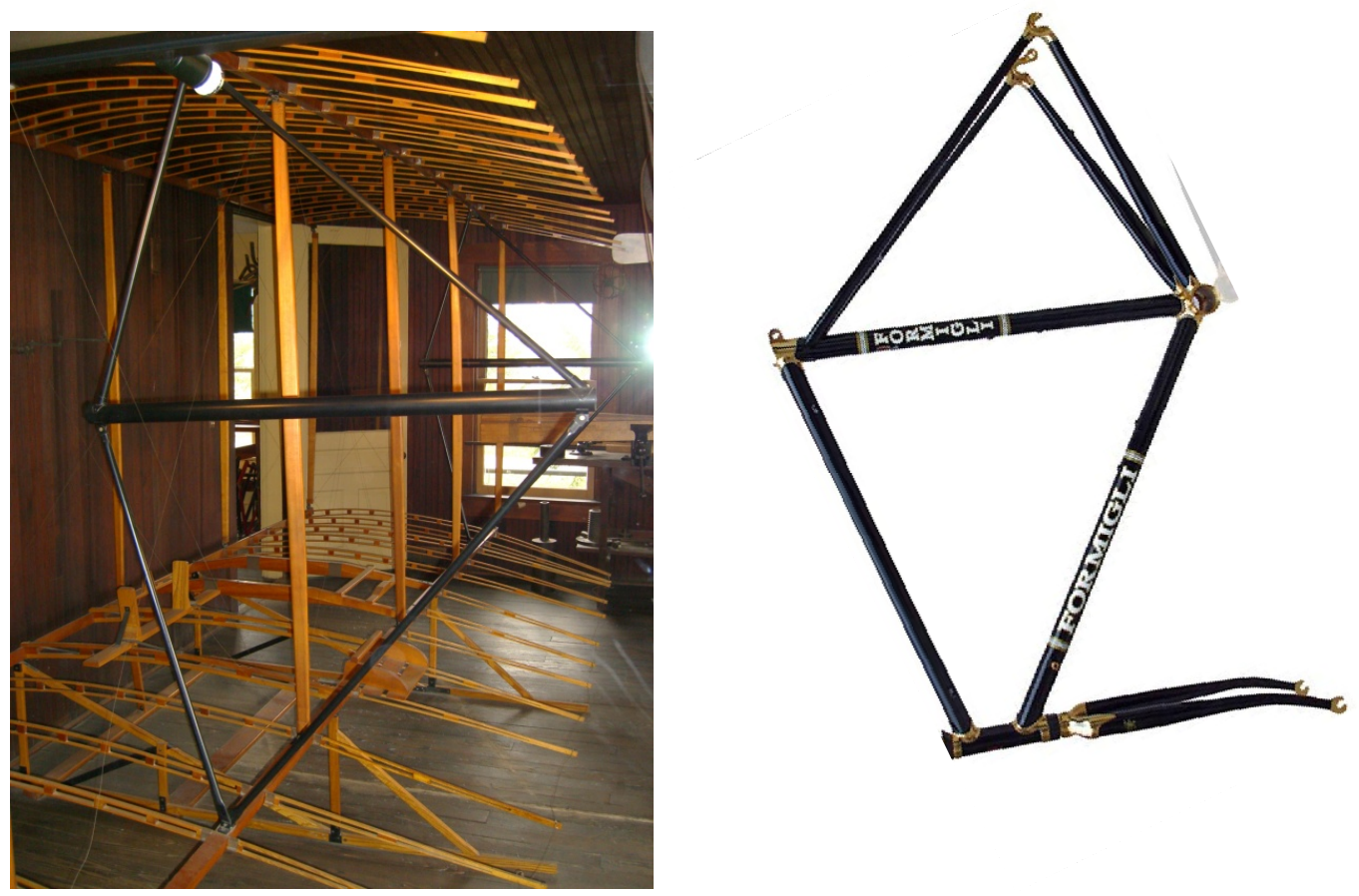

Figure 6: Similarities between Wright aircraft structures and bicycle frames.

Note the similar structures in this propeller shaft support structures on the left and the standard bicycle frames on the right in the photos above and below. Photo at left taken by author at Greenfield Village in Dearborn, Michigan.

Bicycle frame tubing was also used to enclose and guide the chains that ran from the cog on the engine output shaft to the propeller drive sprockets. The same material was used on the pivot for the forward rudder. Truss wires connecting the upper and lower wings were made from fifteen gauge bicycle spokes. These spokes were attached to handmade steel fittings that were also brazed together using similar techniques employed in bicycle frame construction.

Bicycle chains saw extensive use on the 1903 aircraft as well. In addition to the timing chain on the engine, portions of the wing warping control linkage were also made 
from standard bicycle chains. ${ }^{149}$ The wing warping and rudder control linkage was operated through the use of a U-shaped cradle that wrapped around the pilot's hips as he lay on top of the wing. In order to operate the system the pilot simply shifted his hips toward the direction in which he desired to turn, mimicking the movements made by a bicycle rider maintaining their balance.

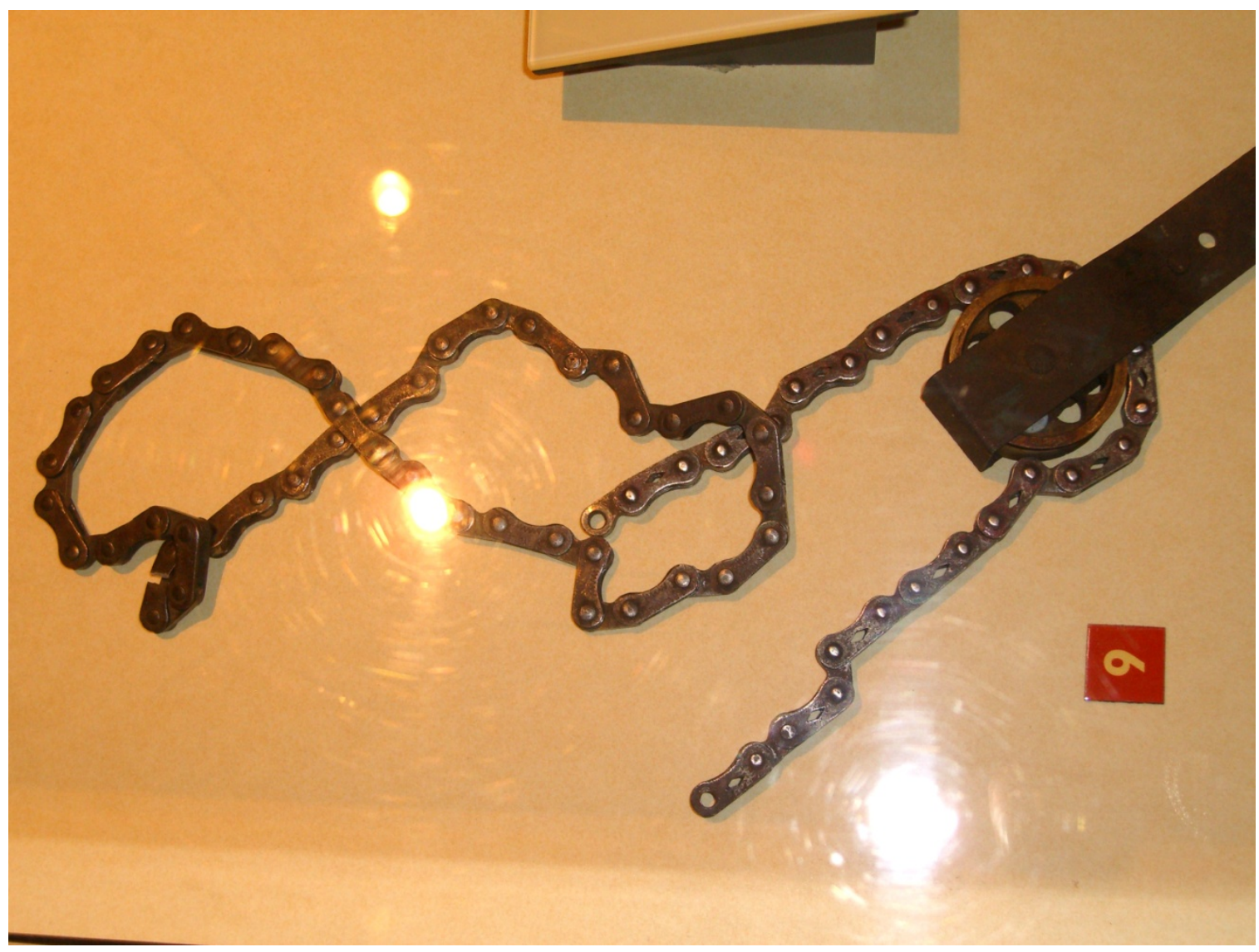

Figure 7: Fragment of wing warping control linkage.

The linkage fragment pictured above is located at Carillon Park Museum in Dayton, Ohio. This example in an original piece taken from the 1905 Flyer. The 1903 Flyer used a very similar linkage. Photo taken by author.

${ }^{149}$ See figure 7. 
A new accessory to the 1903 aircraft was a sixty foot long wooden monorail that was used for the aircraft to roll along as it reached the takeoff air speed. The airplane was designed to roll on a pair of repurposed Van Cleve bicycle hubs that ran on top of the pine two by four monorail. One hub was attached at the axle to an earthbound starting truck that the rear of the aircraft rested on. This truck was designed to roll down the track on the center portion of the hub shell with the spoke flanges acting as guides similar to the lips on the inside edge of a railroad car's wheels. A second bicycle hub was attached to the nose of the aircraft to keep it tracking straight in tandem with the starting truck as the two rolled down the starting rail together.

With the fabrication of the airplane complete and the successful testing of the replacement engine, the Wrights were ready to travel to Kitty Hawk. They arrived at their proving grounds September $25^{\text {th }}$ and quickly set up camp. After this they resurrected the 1902 glider for further testing while they waited for the 1903 machine to be delivered. By October $8^{\text {th }}$ the disassembled aircraft arrived and construction began the following day. It was nearly a month later that the Wrights completed the assembly of their latest prototype.

During initial ground-based engine testing on November $5^{\text {th }}$, the propeller shafts failed. The broken shafts were shipped back to Dayton where they were repaired by Charlie Taylor who stayed behind to run the bike shop. Octave Chanute arrived November $6^{\text {th }}$ in hopes of seeing the Wrights' aircraft in flight only to find that the aircraft was not operational. During the following week Chanute examined the Wrights' machine and offered his criticisms of it. Chanute was especially critical of the chain drive system used to power the propellers. He claimed there was a twenty percent power loss 
between the engine and the propellers as a result of the inherent drag within the system. The Wright brothers estimated a loss of only five percent, but had never tested it. ${ }^{150}$ The five percent figure was likely based on the drag Orville and Wilbur sensed during the many years they spent turning bicycle cranks by hand that were attached to a wheel via a similar chain drive system. The Wright brothers' success was riding on this figure being correct. If Chanute, who had far more engineering experience than both Wilbur and Orville combined was correct, they had no hope of ever getting off the ground with the horsepower figures their engine produced. It seemed as if the Wrights tested nearly every aspect of their aircraft except this critical drive train component. This may have been a result of a simple oversight, but their meticulous testing habits used on the rest of the aircraft suggest that they thought testing this component was unnecessary. Nevertheless, amid the sands of Kill Devil Hills the brothers developed a test to put the issue to rest. Fred Howard explains,

Suspending one of the drive chains over a sprocket wheel, they hung bags of sand on either end approximately equal in weight to the pull on the chains when driving the propellers, then slowly added weight to one side until the sprocket wheel began to move. The loss due to friction, calculated from the added weight, was just about equal to their original estimate of five percent. ${ }^{151}$

This experience demonstrates how integral the mechanical understanding gained in the bicycle shop was to preparing the Wrights as engineers. When this incident is viewed without taking into account the brothers' experience as bicycle mechanics it appears as if the Wrights developed their five percent drag figure through omniscience.

${ }^{150}$ Crouch, Bishop's Boys, 261. It is important to note that while the chain-drive system used to transfer power to their propellers was bicycle inspired, these were not bicycle chains. The chains that the Wrights employed for this purpose were over twice the size of a standard bicycle chain.

${ }^{151}$ Howard, 119. 
However, when analysis of such events is combined with a more detailed examination of their past, the explanation is a bit less magical, but much more credible.

Any offence taken by the Wright brothers over Chanute's poorly informed opinion of their chain drive system were minor compared to another more serious faux pas he unknowingly committed while in Kitty Hawk. Constantly on the hunt for the latest and greatest aircraft technology, Chanute sought to buy aircraft built by other aviation pioneers that he thought were promising. One aircraft that Chanute had his heart set on, and was seriously considering purchasing, was a machine made by the French Government with the exorbitant asking price of $\$ 100,000$ ! Amazingly, given the price, the machine was broken and in need of repairs. Chanute asked if the Wrights would repair and pilot the machine for him if he purchased it. Orville wrote to his father of the experience, “[Chanute] thinks we could [make it fly]! He doesn't seem to think our machines are so much superior as the manner in which we handle them. We are of just the reverse opinion." 152 Rather than judging the Wrights primarily as expert engineers leading the field of aviation, he instead saw them as seasoned pilots who utilized their special measure of aircraft handling skills to surpass their professional engineer competitors. It is likely that Chanute's high opinion of the Wrights' piloting skills was influenced by their reputation as strong cyclists, but without records to corroborate this, it is admittedly only speculation. At any rate, by November $12^{\text {th }}$ Chanute gave up on the Wrights having a serious shot at success that year and left the camp just six days after he arrived. $^{153}$

\footnotetext{
${ }^{152}$ Wright and Wright, Papers, 381.
}

${ }^{153}$ Arthur G. Renstrom, Wilbur and Orville Wright: A Chronology Commemorating the Hundredth Anniversary of the Birth of Orville Wright August 19, 1871, (Washington D.C.: Library of Congress, 1975), 13. 
Ground testing resumed when the repaired propeller shafts arrived on November $20^{\text {th }}$, but the testing remained problematic. Throughout the engine testing, both before and after the shaft repair, the sprockets attached to the propeller shafts did not stay tight as they were shaken loose by the rough running, often misfiring engine. ${ }^{154}$ Remembering the strength of the glue Orville used to attach bicycle tires to rims, he decided to apply the same glue to the threads that fastened the sprocket to the propeller shafts thereby solving the problem and holding the sprockets tight. ${ }^{155}$

The success was short lived however as cracks were again found in the propeller shafts in an inspection made following the ground tests. Orville left for Dayton on December $3^{\text {rd }}$ to procure higher grade steel shafts and returned to the camp nine days later with the new materials. The improved propeller shafts held up well as ground testing proved that the engine and propellers were capable of producing the required thrust the Wrights calculated they needed for success.

Understanding the historical significance of the moment and confident that the next flight would produce success, the brothers decided to flip a coin to determine who would have the first shot at flying the new machine. Wilbur won the toss and set out on December $15^{\text {th }}$ to make history. It was not to be the successful flight they hoped for as the downhill take-off that the brothers arranged complicated the test, leading to a flight of just over one hundred feet that ended in a crash. Wilbur emerged unhurt, but the same could not be said of the aircraft. The following day was spent repairing the machine and planning for additional testing. ${ }^{156}$

\footnotetext{
${ }^{154}$ Wright and Wright, Papers, 380, 384.

${ }^{155}$ Ibid, 384; Crouch, Bishop's Boys, 261; Howard, 125.

${ }^{156}$ Wright and Wright, Papers, 394; Crouch, Bishop's Boys, 264-265.
} 
Learning from the failures of the previous test, the brothers set up their start rail on level ground the morning of the $17^{\text {th }}$. It was Orville's turn this time. As the engine warmed up the brothers resolutely shook hands, certain that this flight would be successful. Orville then boarded the aircraft and situated himself within the wing warping control cradle and took hold of the elevator lever with his right hand. Once the anchor rope attached to the tail was released the aircraft rolled on its Van Cleve hubs down the sixty foot track, lifting off after just forty. Orville flew a distance of 120 feet in 12 seconds that day and became the first person to ever fly a powered heavier-than-air aircraft that took off and landed at the same altitude. Wilbur triumphantly declared, "Eureka!" after Orville safely touched down. Three other successful flights were conducted that day with Wilbur making the longest of them at a distance of 852 feet and a flight time of 59 seconds.

That night a telegram was sent home detailing their achievement. ${ }^{157}$ True to form, no wild parties were initiated in Kitty Hawk or Dayton. Instead, the brothers simply enjoyed knowing that they accomplished the first major step in a process that they intended to continue over many years to come.

${ }^{157}$ Wright and Wright, Papers, 397. 


\section{CHAPTER 8}

\section{EPILOGUE}

The study of aerodynamics was forever altered by the Wright brothers. What they accomplished in this field by 1903 was unmatched by their competitors until years later. The same basic principles governing lift and drag that they identified at that time are still in use today. This staggering achievement that occurred over one hundred years ago remains the most celebrated aspect of their lives, and rightfully so. However, this celebration seems to have obscured the history of how they learned to be the world's first aviators.

It is my hope that this history has served to bring to light how, as Wilbur described, "a thousand other factors, each rather insignificant in itself" combined to produce a success that "mere mental ability or inventiveness" could not. ${ }^{158}$ Through a careful analysis of the Wrights' life experiences as well as the technologies and principles they employed in their earlier careers, it becomes clear how the Wright brothers learned to fly. When these experiences combined with the impressions made on them by their family, a more detailed vision of this path toward success in aviation becomes apparent.

The intellectual development of the Wright brothers' approach to flight is just one aspect of this analysis however. Other, more practical reasons exist for understanding this early portion of the Wright brothers' lives. There is the basic consideration that without the ability to build the aircraft that they envisioned they likely would have never gotten off of the ground, an observation that is often forgotten. Moreover, we must keep in mind

\footnotetext{
${ }^{158}$ Wright and Wright, Papers, 731-732.
} 
that the key reason the Wright brothers are remembered as aviators is because they were first. It was the speed of their aircraft development that made them famous.

If we review the Wright's aircraft development process with a hypothetical assumption that they did not have the ability to build their aircraft, the odds that Orville and Wilbur would become the first true aviation engineers are slim. While I admit that hypothetical history is a shaky proposition, what I am endeavoring to do in the following is not to predict an alternate course of events, but rather to identify the potential challenges such a situation would create.

In a best case version of this hypothetical scenario the Wright brothers would have possessed large sums of money. They could then use the money to hopefully find and hire qualified craftspeople that could do the appropriate woodworking jobs to fabricate their aircraft. Such a hypothetical would also require that the craftspeople work quickly and follow directions precisely, a challenge that is rarely accomplished in the real world even when employer and employee each have the best of intentions. Moreover, for quick success there would need to be no communication breakdown between the hypothetical theoretician Wrights and the craftspeople they hired.

Our hypothetical theoretician Wright brothers would also need to spend more time testing the strength of all of the materials they used. Or, they would need to rely on the knowledge of the craftspeople to have a good idea of what the materials could handle. The latter scenario would be difficult because the craftspeople would need a working knowledge of what stresses were placed on the airframe without an intimate understanding of the aerodynamic forces applied to the structure. 
For more precise aerodynamic data to be used later in the testing, these hypothetical Wright brothers would likely have difficulty designing a testing apparatus for their experiments, thereby slowing down this leg of their aircraft development. Once this problem is solved another is created. If new aerodynamic data was acquired after construction on the aircraft began, changes must be made to the prototype aircraft to incorporate the appropriate improvements into the structure. For this to happen, the Wrights would first need to communicate to the workers, only during the hours they were employed, what changes were to be made. Quick success at this stage would also require crystal clear communication.

Testing would become complicated as well because the Wrights would have needed to take their team to Kitty Hawk with them in order to assemble and repair the aircraft during the testing. The real Wright brothers tried at one point to employ a local Kitty Hawk resident to help with their experiments only to have the employee quit in disgust. ${ }^{159}$ The reason for this probably had more to do with the miserable living conditions they experienced while camped out on the sands of Kill Devil Hill than with the personalities of either brother or the employee. It is reasonable then to speculate that other employees in this hypothetical might also abandon the Wrights, killing their experiment before it was ever completed.

This speculation is not intended to rule out the possibility of success as this is unknowable. However, we can be certain however that being the first successful aviators would have been much more challenging and certainly would have taken longer. The extra time required may have relegated them to a similar status achieved by Glenn Curtiss, a potent aviation innovator, but not a founding father of flight. Closer

\footnotetext{
${ }^{159}$ Wright and Wright, Papers, 374-375.
} 
examination of the experiences of the Wrights prior to 1900 demonstrates how critical the knowledge gained during this period was to their achievements and status as the world's first true aviators.

Taking this longer view on the Wright brothers' history may lessen their mystique as natural genius inventors but it cannot diminish the enormity of their accomplishments. In my estimation, this perspective actually increases the measure of respect the Wrights deserve as it emphasizes the hard work they expended challenging themselves to accomplish new things. Unlike the prophetic visions of new inventions that some inventors during this same period described, the Wright brothers learned by doing and became the renaissance men of America's nineteenth century independent inventors. 


\section{BIBLIOGRAPHY}

Adams, Noah. The Flyers: In Search of Wilbur and Orville Wright. New York: Random House, 2003.

A brief history of the Wright brothers that offers a human interest style journalistic review of their achievements. There is almost no mention of any event prior to the Kitty Hawk trials. The thesis could best be described as trying to understand what the Wright brothers saw and felt as they went about pioneering human flight. No technical information is offered in this book. If it has any value to my argument, it serves to reinforce that little effort has been made to truly understand how the Wright brothers developed the skills and concepts that later resulted in the invention of the first successful airplane.

Anderson, John D. Inventing Flight: The Wright Brothers and Their Predecessors. Baltimore: Johns Hopkins University Press, 2004.

This is a great book outlining the more technical aspects of the Wright brothers' development of aerodynamic theory. This history is contained within its proper historical context including brief histories of those who went before them and the theories they developed. This volume helps to establish what the Wrights learned from other aviation pioneers and what they developed on their own. There is no information concerning the early years of the Wrights beyond a couple of pages that offer no significant direct connections between their education/experience and their engineering abilities prior to 1896. Very little consideration is given to the period between 1896 and 1899 either.

Bedini, Silvio A. Thinkers and Tinkers: Early American Men of Science. Ann Arbor: Edwards Brothers, 1983.

Bedini argues that American inventors and mathematicians of the late eighteenth century and early nineteenth century were critical to establishing American identity and unity. The work of these men later influenced other American inventors that were active in the late nineteenth and early twentieth centuries. While there does not appear to be a direct connection to the Wright brothers, this volume offers a history of the men that laid the groundwork for the next generation of American inventors.

Bijker, Wiebe E. Of Bicycles, Bakelites, and Bulbs: Toward a Theory of Sociotechnical Change. Cambridge, Massachusetts: The MIT Press, 1995.

This book contains another history of the development of the bicycle and the bicycle industry. The author uses the development of the bicycle and the social changes it 
brought as a metaphor and a standard for examining other inventions and their effect on society.

Boorstin, Daniel J. The Republic of Technology: Reflections on Our Future Community. New York: Harper \& Row, 1978.

This now classic text on invention and technology discusses how technological innovation has had a revolutionary effect on American society. Boorstin offers a framework for analyzing and identifying how and why technology has changed modern life.

Brunsman, Charlotte K. and August E. Brunsman. "Wright \& Wright Printers: The Other Career of Wilbur and Orville." The Journal of the American Printing History Assocation, Vol 10, Number 1, 1988.

This is a solid source of information on the Wright brothers' printing business that includes information on how Wilbur and Orville came to be involved in the industry. Tom Crouch claims that this article is the most complete source of material on this stage in the Wright brothers' lives and I agree with him. The thesis here is that the brothers' experience in printing was an important step in preparing them for their experience in the bicycle business and later in their aircraft design and manufacturing business. The authors draw on both primary and secondary sources but place greater emphasis on their examination of the primary sources in their analysis.

Chanute, Octave. Progress in Flying Machines. Long Beach: Lorenz \& Herweg, 1976.

This book was originally published in 1894 and was studied intensively by the Wright brothers. The book functions as an encyclopedia of aviation efforts up until the year it was published. Much of the Wrights' understanding of aerodynamics in their first year of experimentation came from this source and their correspondence with Chanute.

Combs, Harry with Martin Caidin. Kill Devil Hill: Discovering the Secret of the Wright Brothers. Boston: Houghton Mifflin, 1979.

A biography of the Wright brothers written by a pilot with an education in economics that worked professionally in the aviation industry for a number of years. Combs reviews the history of the Wright brothers' testing and development of their aircraft. Like all biographies of the Wrights, the early years are glossed over and no attempt is made to understand how the Wright brothers gained the skills to accomplish what they did. Combs however is true to the primary sources but does not utilize them to expand upon what was already published at this time about their early lives. This strengthens my argument that the historiography is incomplete and flawed. 
Crouch, Tom D. A Dream of Wings: Americans and the Flying Machine, 1875-1905. New York: W. W. Norton \& Company, 1981.

An overview of the history of aviation in America between 1875 and 1905. There is a good section on the Wright brothers containing some information that is not included in some of Crouch's other books on the subject.

Crouch, Tom D. The Bishop's Boys: A Life of Wilbur and Orville Wright. New York: W.W. Norton \& Company, 1989.

Crouch presents a detailed account of the lives of the Wright brothers drawing almost exclusively on primary sources. This detail includes the early years as children, teenagers, and young adults. Their relationships with various family members are examined along with a fairly thorough account of their business dealings and inventions prior to their construction of aircraft. There is also a full description of their lives after 1903 however, much of this information is beyond the scope of my thesis.

Crouch, Tom D. "How the Bicycle Took Wing." Invention \& Technology Magazine, Vol. 2, Issue no. 1 (Summer 1986).

This is a brief article on the importance and influence of the bicycle in America in the late nineteenth century. Crouch reviews how many aviation pioneers saw a connection between bicycle riding and flying. An account of the timeline of the Wrights' bike business is made here also. The main importance of this article is that it emphasizes the need for an aircraft to be unstable in order to be properly controlled by the pilot. This is a key breakthrough for the Wright brothers that came as a direct result of their experience controlling unstable bicycles. Sadly, at the end of the article Crouch seems to dismiss their background in bicycles as having little importance in the overall scheme of devising the first working aircraft. This is where I hope to revise the historiography of the Wright brothers.

Crouch, Tom D. "Kill Devil Hills, 17 December 1903." Technology and Culture. Vol. 40, No. 3 (July, 1999): 594-598.

This article primarily discusses the importance of the bicycle in influencing the Wright brothers' aviation efforts. The Wright brothers' efforts in photography are also discussed. This article is a good source for various predictions correctly made by aviation pioneers before the Wrights' success predicting that bicycle mechanics or someone using the lessons learned in bicycle technology would crack the problem of flight. The main thesis is that the Wright brothers had a background in many different technologies and they used them to succeed in developing the first viable aircraft. 
Crouch, Tom D. "Why Wilbur and Orville? Some Thoughts on the Wright Brothers and the Process of Invention." In Inventive Minds: Creativity in Technology, edited by Robert J. Weber and David N. Perkins, 80-92. New York: Oxford University Press, 1992.

This article reviews the mental process of invention used by the Wright brothers in developing their aircraft. Crouch's thesis is that what made the Wright brothers special was their ability to visualize abstract ideas such as lift and drag into models and measuring devices used to generate data that could be used in designing wings. The author claims that this ability is what made the Wright brothers geniuses and I am inclined to agree. This thesis in line with the analysis made by Jakab in Visions of a Flying Machine. This is to be expected however as they work together at the Smithsonian. Crouch also briefly reviews the impact their family and business ventures had on their development as engineers.

Crouch, Tom D. and Peter L. Jakab. The Wright Brothers and the Invention of the Aerial Age. Washington D.C.: National Geographic, 2003.

This book represents the most recent addition to the historiography on the Wrights by Crouch and Jakab in monographic form. It is primarily an overview of the aeronautical work of the Wright brothers that contains a wealth of high resolution images to accompany the story. The Wrights ability to visualize engineering solutions is emphasized again in this book as it is in Jakab's 1990 book and Crouch's article published two years later. There are no new theses offered here, just a concise review of the main points of Crouch and Jakab's earlier biographical works to mark the centennial of flight.

Evans, Quinn. Historic Structure Report: The Wright Cycle Company Building (HS-01). Dayton: Dayton Aviation Heritage National Historical Park, 1999.

This is a report ordered by the National Parks Service offering details regarding the history of the 22 South Williams St. bike shop location. The report includes information such as shop layout including which machines were in use at the shop as well as a brief history of other businesses that used the building. This could be helpful in making citations regarding machines that the Wright brothers used and how they organized their shop.

Ferguson, Eugene S. Engineering and the Mind's Eye. Cambridge, Massachusetts: The MIT Press, 1992.

Ferguson explains how successful engineers often visualize the problems they solve and the solutions they create. Jakab and Crouch have identified this ability in the Wright 
brothers and see it as critical to their success. Ferguson's analysis of this ability can shed light on how the Wright brothers may have used this ability to accomplish what they did.

Fisk, Fred C. and Marlin W. Todd. The Wright Brothers: From Bicycle to Biplane. West Milson, Ohio: Fred C. Fisk and Marlin W. Todd, 1995.

While this book is essentially a scrapbook of information about the Wright brothers, it contains an outstanding number of primary sources. The book is full of illustrations including woodcuts, ads, papers, photos, and drawings by the Wright brothers. Much of this primary source material is unavailable in other books on the Wright brothers. There is no central thesis here as it is more of a reference book chronicling the major points in the Wright brothers' development as engineers.

Freudenthal, Elsbeth E. Flight into History: The Wright Brothers and the Air Age. Norman, Oklahoma: University of Oklahoma Press, 1949.

An earlier biography of the Wright brothers that helps to prove that histories of the Wright brothers contain little information concerning their early years and give little credit to the role that those experiences played in preparing the Wrights to be the world's first heavier-than-air aviators. The portion of pages devoted to their earlier years is a scant fourteen of the two-hundred and fifty-three page history.

Grassick, Mary. Historic Furnishings Report: The Wright Cycle Company Building. Dayton: Dayton Aviation Heritage National Historical Park, 2007.

This is a report generated by the National Park Service to serve as a definitive source for examining the history of the 22 South Williams Street location for the Wright Cycle Company. The report includes information on the shop arrangement and the various machines used at the shop. Also included are details on the Wright's printing business that also operated out of this location. This report contains high resolution historical photos and illustrations that are useful in examining the tools and construction techniques the Wrights employed.

Goddard, Stephen B. Race to the Sky: The Wright Brothers Versus the United States Government. Jefferson, North Carolina: McFarland \& Company, 2003.

The title of this book suggests that it is a history of the court battles over the Wright brothers' airplane patents, however it is more of a history of the competition between the Wrights and their contemporaries up to 1904. The book offers insight into attempts at flight made by the Wright brothers' competitors and how they were often funded by the United States Government and/or wealthy investors. The book highlights the Wright 
brothers' refusal of any financial investment from any source, including their friend Octave Chanute.

Heppenheimer, T.A. First Flight: The Wright Brothers and the Invention of the Airplane. Hoboken: John Wiley \& Sons, 2003.

An account of the Wright brothers that seeks to place them in the larger history of the development of flight. Very little attention is paid to any portion of the brothers' lives prior to 1900 . The author has a Ph.D. in aerospace engineering but no advanced training in history. Surprisingly, the book offers very little depth with regards to technical information on the various aspects of the Wright Flyer. This history seems to follow the pattern of other histories that seem to be dumbfounded that "bicycle mechanics" could become great engineers and chalks up much of the brothers' success to innate genius. The main thesis here is that the Wright brothers succeeded where other aviation pioneers failed because they performed more scientific testing.

Herlihy, David V. Bicycle: The History. New Haven: Yale University Press, 2004.

A comprehensive history of bicycles from their inception to the modern day. Generally accepted as the top book on the subject, it provides a good location to gather information that places the Wright's work in bicycles within a broader context. The thesis of the book is that the bicycle is more important to the development of the modern world than it is often given credit for. The book is filled with primary sources such as ads and technical information.

Hindle, Brooke. Emulation and Invention. New York: New York University Press, 1981.

Hindle argues that the inventive process employed by nineteenth century American inventors took on a more prominent visual component than the inventors of the past. The main point of Hindle's argument is that visual thinking often takes the form of emulation and improvement. This thesis seems to dovetail with the work of Peter Jakab who argues that the Wright brothers utilized "visual thinking" to achieve their engineering prowess. This is not surprising as Hindle and Jakab are both Smithsonian alums. Hindle's book is important to my thesis because it provides greater support for my argument that the Wrights' prior experiences in various trades contributed substantially to their ability to build the first successful aircraft.

Honious, Ann. What Dreams We Have: The Wright Brothers and Their Hometown of Dayton, $\mathrm{OH}$. United States: Eastern National, 2003.

One of my favorite accounts of the Wright brothers, this book reviews their lives from the standpoint of how their location in Dayton, Ohio influenced their work. It provides a 
great overview of their accomplishments with enough detail and citations of primary and secondary sources that it can provide a quick reference for answering most questions on the brothers. Honious draws on both primary and secondary sources and has a knack for explaining simply and elegantly the various periods of the Wrights' lives. The thesis here is that all of the accomplishments of the Wrights should be examined in their native context of Dayton, Ohio. By viewing the events within this historical context, historians can gain a more accurate and organic understanding of the Wright brothers' history.

Hounshell, David A. From the American System to Mass Production 1800-1932: The Development of Manufacturing Technology in the United States. Baltimore: The Johns Hopkins University Press, 1984.

A chapter of this book is devoted to the bicycle industry and is specifically focused on the operations and evolution of the Columbia bicycle company. The author outlines specific technologies and processes that were used by this company to produce bikes on a large scale. As the first bicycle manufacturer in the United States, some inferences regarding frame building techniques may be drawn based on the techniques Columbia used. It is also possible that the Wrights used Columbia frame components as the company did sell these to other framebuilders. The author's thesis is that the development of bicycles in America was instrumental in producing a better road system and that the bicycle craze stoked the demand for the automobile that were developed soon thereafter. Additionally, many manufacturing techniques were transferred from bicycle manufacturing to early automobile manufacturing.

Howard, Fred. Wilbur and Orville: A Biography of the Wright Brothers. New York: Alfred A. Knopf, 1987.

This account of the Wright brothers' lives is somewhat similar to the account given by Crouch. The primary difference is that it lacks any detail of the early years of their lives. The other difference is that it is less hagiographic than Crouch's monograph, examining their lives with a critical eye. Howard utilizes primary sources almost exclusively and therefore offers a clear view of the Wrights' work. The weakness here is that this book is a biography first and a history second although it is written very well. A second weakness is that it contains little technical information.

Hughes, Thomas P. American Genesis: A Century of Invention and Technological Enthusiasm. New York: Viking Penguin, 1989.

Hughes has written an outstanding book detailing the effect of the massive technological changes that occurred in America between 1870 and 1970. Very accessible to readers both inside and outside of the academy, Hughes argues convincingly that the inventions and industry of the late nineteenth century created the world that we later occupied. This 
book is applicable to my analysis of the Wright brothers' place in history as inventors and simply as Americans in general during this period.

Jakab, Peter L., Visions of a Flying Machine: The Wright Brothers and the Process of Invention. Washington D.C.: Smithsonian Institution Press, 1990.

Jakab explores how the Wright brothers approached questions regarding human flight. Throughout the book Jakab draws extensively on both primary and secondary sources to assemble his argument. He highlights specific aeronautical developments by the Wright brothers that drew upon their experience riding bicycles and the repurposing of bicycle components. However, he does not explore the various skills and thought processes the brothers developed while building bicycles and printing presses before they began to develop their aircraft.

Keefer, Kathryn A. The Wright Cycle Shop Historical Report. Greenfield Village, Michigan: The Henry Ford, 2005.

This report was put together by a historian working for Henry Ford's Greenfield Village. It reviews the history of the structure and the layout of the shop at the time the Wright brothers conducted business there. Charlie Taylor was employed in the reconstruction of the shop to ensure that the layout maintained historical accuracy and this report helps to corroborate Taylor's memory of the shop. This report is of value to my thesis because it establishes which tools were used by the Wright brothers and how they employed their fabricated engine and line shaft arrangement to power these tools.

\section{Kelly, Fred C. Miracle at Kitty Hawk: The Letters of Wilbur and Orville Wright. New York:} Farrar, Straus and Young, 1951.

This volume is a primary source reader with abridged letters written by the Wright brothers and their correspondents. The letters are organized by subject; however this also results in them being roughly organized chronologically as well. Kelly occasionally interjects comments on the various technological and theoretical developments revealed in the letters. The comments are of little value other than as a summary of the significance of the development and no thesis is argued within these comments. I have compared some of the letters in Kelly with the unabridged letters in McFarland. I have found that in Kelly some paragraphs are out of order and therefore cannot be relied upon for proper context. This problem is compounded when it is viewed in light of the contextual issue of general abridgement. Despite these issues this book is valuable as a quick reference for primary sources organized by subject. 
Kelly, Fred C. The Wright Brothers: A Biography Authorized by Orville Wright. New York: Harcourt, Brace and Company, 1943.

Most historians consider much of the facts presented in this volume to be suspect as they often are not corroborated by the actual primary sources. Nevertheless it is the official biography of the Wright brothers and as such it has a certain authority that other biographies do not. Where Kelly agrees with other historians it can only serve to strengthen the validity of these points.

Langley, Samuel Pierpont. Memoir on Mechanical Flight part 1. New York: Smithsonian Institution Press: 1973.

Originally published in 1911 this book contains Langley's thoughts and figures regarding the mechanics and aerodynamics of flight. It offers a good look into the thinking of the Wright brothers' main competitor. Comparing the information contained here with the information in the Wrights' notes on flight will illuminate where the Wright brothers surpassed Langley in their understanding of aircraft construction and aerodynamic theory. This is useful because Langley was a scientist with $\$ 70,000$ given to him by the Federal Government and the Smithsonian who was not able to crack the problem of flight before the Wright brothers even with these vast resources and a team of engineers. There is something critically different in the Wright brothers' background that made their success possible.

Lienard, John H. How Invention Begins: Echos of Old Voices in the Rise of New Machines. New York: Oxford University Press, 2006.

Lienard examines the invention process and includes a chapter on flight. He argues that the airplane was invented by "a Zeitgeist" rather than by one or two people. He reviews the work of early aviation pioneers such as Ibn Firnas, Cayley, Penaud, Giffard, Stringfellow, Lilienthal, Maxim, Chanute, Langley, and Santos-Dumont. Lienard makes some sound points in his argument which is very simply boiled down to the idea that many people were working on the problem of flight, they gleaned information from one another, and as a result, no one person invented the airplane. Although, Lienard freely acknowledges that he believes the Wright brothers were the first in flight when this achievement is given a number of qualifying statements beforehand. These are first to fly a powered aircraft that was controlled by an on board pilot, that took off under its own power from level ground, and landed at the same elevation safely.

Lilienthal, Otto. Birdflight as the Basis of Aviation: A Contribution Towards a System of Aviation. New York: Longmans, Green, and Co., 1911.

Lilienthal's book serves to detail what he understood of the dynamics of flight. This is the same book that Octave Chanute provided for the Wright brothers to study during their 
aircraft experiments. As such this book can provide a clearer understanding of what information the Wright brothers had available to them.

Macy, Sue. Wheels of Change: How Women Rode the Bicycle to Freedom. Washington D.C.: National Geographic, 2011.

Macy outlines the effect of the bicycle on the development of the women's liberation movement. This book is basic and short but offers a good reference on the subject that serves as a solid jumping off point for further research on the subject.

Marx, Leo. The Machine in the Garden: Technology and the Pastoral Ideal in America. New York: Oxford University Press, 1964.

Leo Marx offers an eloquent examination of how science and technology has been understood by humanity first a proof that God existed only later to decide it proved the opposite. This serves as a good volume for analyzing the impact of science and technology on American society during the lives of the Wright brothers.

McMahon, John R. The Wright Brothers: Fathers of Flight. Boston: Little, Brown, and Company, 1930.

This is the first biography published on the lives of the Wright brothers. It is rarely cited in modern histories on the Wrights due to various inaccuracies and imagined dialogs common to biographies from this era. Like nearly all of the Wright biographies to follow, little credit is given to the Wrights' work in printing and bicycles toward their success in airplanes.

National Air and Space Museum. Otto Lilienthal and Octave Chanute: Pioneers of Gliding. Washington D.C.: Smithsonian Institution, 1980.

This is a short booklet from the National Air and Space Museum that offers a brief history of Lilienthal and Chanute. This Lilienthal history is valuable to my study because nearly every book on his life is written in German.

O’Neill, John J. Prodigal Genius: The Life of Nikola Tesla. New York: Ives Washburn, 1944.

The classic biography of Nikola Tesla offering insights into how this Wright brothers contemporary had much in common with the inventors from Dayton. 
Pridmore, Jay and Jim Hurd. The American Bicycle. Osceola, Wisconsin: Motorbooks International, 1995.

This is a basic history of the bicycle in America similar to the Herlihy book but with less depth. Basic information regarding bicycle construction, racing, and its role in American culture is examined. The thesis is simply that the bicycle is an important part of American history and has left its mark on American culture, transportation, and recreation. I see this book as valuable to my thesis in that it offers further support of the information offered in the Herlihy and Hounshell books.

Renstrom, Arthur G. Wilbur and Orville Wright: A Chronology Commemorating the Hundredth Anniversary of the Birth of Orville Wright August 19, 1871. Washington D.C.: Library of Congress, 1975.

This is a good reference book for keeping track of the chronology of the Wright brothers' lives. There is almost no information prior to 1890 offered however. Another great resource offered in this book is a copy of all of their flight logs.

Roseberry, C.R. Glenn Curtiss: Pioneer of Flight. Garden City, New York: Doubleday, 1972.

This biography covers Curtiss' life and how it often crossed paths with the Wrights eventually leading to a merging of their two companies. Curtiss is important to my argument because he also started in bicycles before moving into aircraft construction. Not much information is offered on the portion of Curtiss' life when he was in the bicycle business, but there is enough to make some salient connections between the Wrights and Curtiss in their bicycle efforts.

Shagena, Jack L. How the Wright Brothers Got it Right: Engineering and Invention of the Airplane (for non-technical readers). U.S.A.: Jack L. Shagena, Jr./InstantPublisher.com, 2007.

This book was self-published by a professional engineer and amateur historian. It is quite well written and offers technical information on the Wright Flyer and the history of its technical development in a way that is easily accessible for non-engineers. This book is a good companion to the Anderson book: Inventing Flight. Shagena's thesis is that the Wright brothers were successful because they employed careful testing techniques, taking nothing for granted, and measuring as much as possible. These careful observations were then used to learn from their mistakes and to improve steadily until they were successful. There is no information on the brothers' history prior to their embarkation on intensive flight research in 1896. Even so, there is extremely little information on the years between 1896 and 1899. 
Simonton, Dean Keith. "Exceptional Creativity Across the Life Span: The Emergence and Manifestation of Creative Genius." In The International Handbook on Innovation, edited by Larisa V. Shavinina, 293-308. San Diego: Elsevier Science, 2003.

This article offers some incredible insights into why the Wright brothers developed their creative genius as they did. It seems that the Wrights took an unusual path to this destination however Simonton shows that this is common among creative geniuses. $\mathrm{He}$ does not comment specifically on the Wright brothers but his data shows how and when genius happens and the Wright brothers fit right into the profile with remarkable ease.

Stearns, Peter N. "Progress and Flight: An Interpretation of the American Cycle Craze of the 1890s." Journal of Social History Vol. 5, No. 2 (Winter, 1971-1972): 235-257.

This article looks at the foundations of the cycling craze and how it affected American culture. Stearns argues that the cycle craze embodied the desire of Americans to break out of the constraints of Victorian society and "fly" away from these concerns. He sees cycling as a mode of escapism that led toward a new era in American history that ushered in the age of the automobile and a quantum leap in the women's liberation movement. This article is a good source for establishing a context for the bicycle industry that the Wright brothers participated in.

Taylor, Charles E. with Robert S. Ball. "My Story.” Air Line Pilot, (April 2000): 22.

A brief interview with the Wright brothers' employee and machinist, Charlie Taylor. Much of the information available today about Taylor comes from this brief article that was originally published in Collier's in 1948. It details how he met the Wright brothers and the work he did for them such as machining their bicycle hubs, bicycle repairs, retail sales, and his assistance with the design of the first motor ever successfully used to power an airplane. Taylor did all of the machining of the Wright Flyer motor and worked as the Wright's mechanic as they demonstrated the airplane to the public and the military. This is a good source for information outlining how much the Wrights knew with respect to machining as well as outlining how Taylor acted as a "third Wright brother" that is often forgotten in the Wright brothers' story.

Winters, Nancy. Man Flies: The Story of Alberto Santos-Dumont, Master of the Balloon. Hopewell, New Jersey: The Ecco Press, 1998.

An interesting account of Santos-Dumont that is instructive because Dumont was unaware of the Wright brothers' first flight when he developed his own heavier-than-air aircraft. Dumont remained unaware of the Wrights' success when he made his first flight Oct. 22 1906. Dumont approached the problem of flight from an entirely different angle starting with airships before moving to heavier-than-air aircraft. As the son of a wealthy Brazilian millionaire Dumont had much more time and money to devote to his aircraft. 
Winters draws only upon secondary sources here and offers a very brief, superficial account of Dumont's aviation exploits. The bibliography is a good source for more detailed accounts however.

Wolko, Howard S. The Wright Flyer: An Engineering Perspective. Edited by Howard S. Wolko, Washington D.C.: Smithsonian Institution Press, 1987.

A collection of essays on the engineering aspects of the Wright Flyer. Each essay has a specific emphasis such as stability, propulsion, structure, etc. It is a good source for establishing an argument regarding the Wrights that requires engineering expertise to back it up. The authors have drawn on primary sources, and then in some cases, have made their own analysis utilizing mathematics, modern aerodynamic theory, and computer models in an effort to better understand how and why the Wright Flyer worked.

Wright, Milton. A Higher Moral and Spiritual Stand: Selected Writings of Milton Wright. Edited by Timothy S. G. Binkley. Lanham, Maryland: The Scarecrow Press, 2009.

A collection of editorials written by Bishop Milton Wright that were printed in The Religious Telescope, a weekly paper published by the United Brethren in Christ. This is a great volume for referencing Bishop Wright's perspective on Christian theology. An examination of Bishop Wrights teachings will reveal which Christian values were emphasized in the Wright home and how these values may have affected the personality and character of Orville and Wilbur.

Wright Family, Milton. The New Testament, King James Version. Wright State University Archives, Wright Brothers Collection, Box 2 item 11, MS-1 1877.

This Bible is one of many in the Wright State Archives belonging to the Wright family. It is a pocket sized edition measuring approximately 4" tall and 3" wide. Page markers with reference numbers help identify which passages were important to the family.

Wright, Orville. Central High School Report Card. Wright State University Archives, Wright Brothers Collection, Series II, subseries 6, box 6, file 3, 5.

This report card demonstrates that Orville was not a "straight A" student and was known to have his mind elsewhere when in class. The report card also shows which subjects Orville studied as well as his tendency to come through in the clutch, as his grades improved somewhat at the end of the year relative to his midterm grades.

Wright, Orville, Woodcuts. Wright State University Archives, Wright Collection, Part II, Series II, Subseries 8, Box 6, File 12. 
These woodcuts were made by Orville for use by Wright and Wright Job Printers. They demonstrate the woodcarving skills developed by Orville that were later transferrable to their work with wood propellers and airframes.

Wright, Susan Koerner. Charles Davies, Elementary Algebra: Embracing the First Principles of the Science, (Cincinnati: A.S. Barnes \& Co., 1954), Wright State University Archives' Wright Brothers Collection Part I: The Technical Library, autographed by Susan Koerner.

This algebra textbook helps to establish the extent of mathematic knowledge possessed by the mother of the Wright brothers. This is important because it shows which concepts and methods she may have taught to her sons.

Wright, Wilbur and Orville Wright. The Beginning of Human Flight (pamphlet). New York: The Wright Company, 1916.

This pamphlet was used at an exhibition of the Wright Flyer in 1916 to briefly explain to visitors the history of the development of the aircraft. The pamphlet is useful in establishing what Orville saw as the "official" version of the events.

Wright, Wilbur vs Orville Wright. Court Case 1892 concerning who does the most work, Wright State Archives, Wright Brothers Collection, series II, subseries 9, box 6, file.16.

Wilbur put together this fictitious legal brief to settle a dispute between him and Orville regarding work divisions at their businesses. The brief successfully defused the situation with a good dose of humor and honesty. This document not only speaks volumes about who the Wright brothers were as individuals, it also establishes that they took on contract work building letter presses for other printers.

Wright, Wilbur and Orville Wright. The Papers of Orville and Wilbur Wright: including the Chanute-Wright letters and other papers of Octave Chanute. ed. By Marvin W. McFarland. New York: McGraw-Hill, 2001.

This is a primary source reader for the Wright brothers' communications with early aviation engineer Octave Chanute and the Smithsonian Institute. This is the most valuable volume to my thesis as it contains the thoughts, questions, and problems the Wrights encountered as they designed and built the first aircraft.

Wright, Wilbur and Orville Wright. The Published Writings of Wilbur and Orville Wright. ed. by Peter L. Jakab and Rick Young. Washington: Smithsonian Institution Press, 2000. 
A primary source reader that contains the writings of the Wright brothers that were published in various magazines and newspapers. The brothers also comment on various controversies such as the Langley priority claims and general development in the field of aviation. A good source for interviews that explore the physical and thought processes that the Wright brothers went through as they developed the first airplane.

Wright, Wilbur and Orville Wright, United States Patent No. 821,393. 1906.

This is the patent for the Wright brothers' wing warping technology filed with the U.S. Patent office March 23, 1903 and granted May 22, 1906. This document explains the technology operates and what it is designed to do.

Wykeham, Peter. Santos-Dumont: A Study in Obsession. New York: Harcourt, Brace and World, 1962.

This is a biography of Santos-Dumont focusing on his aeronautical endeavors. Much more in-depth than the Winters book, it offers more specifics on the thought processes and engineering employed by Santos-Dumont to produce what he and his countrymen believed was the first working airplane. Ironically, the Wrights' airplane was far superior and had flown years earlier. Even so it is instructive to see how Santos-Dumont used the same Lilienthal and Chanute data to come up with an aircraft that had little in common with the Wright Flyer. Santos-Dumont's design fell prey to the same issues of predecessors to the Wrights; namely, a failure to understand the need for an aircraft to be unstable in roll for it to be controllable. 